\title{
Impacts of Broad-Scale Surface Freshening of the Southern Ocean in a Coupled Climate Model $^{\mathscr{O}}$
}

\author{
ARIAAN PURICH \\ Commonwealth Scientific and Industrial Research Organisation, Oceans and Atmosphere, Aspendale, Victoria, \\ and Climate Change Research Centre and ARC Centre of Excellence for Climate System Science, University \\ of New South Wales, Sydney, New South Wales, Australia

\section{MATTHEW H. ENGLAND} \\ Climate Change Research Centre and ARC Centre of Excellence for Climate System Science, University of \\ New South Wales, Sydney, New South Wales, Australia

\section{WENJU CAI ${ }^{\mathrm{a}}$ AND ARNOLD SUlLIVAN} \\ Commonwealth Scientific and Industrial Research Organisation, Oceans and Atmosphere, Aspendale, \\ Victoria, Australia

\section{PAUL J. DURACK} \\ Program for Climate Model Diagnosis and Intercomparison, Lawrence Livermore National Laboratory, \\ Livermore, California
}

(Manuscript received 13 February 2017, in final form 26 December 2017)

\begin{abstract}
The Southern Ocean surface has freshened in recent decades, increasing water column stability and reducing upwelling of warmer subsurface waters. The majority of CMIP5 models underestimate or fail to capture this historical surface freshening, yet little is known about the impact of this model bias on regional ocean circulation and hydrography. Here experiments are performed using a global coupled climate model with additional freshwater applied to the Southern Ocean to assess the influence of recent surface freshening. The simulations explore the impact of persistent and long-term broad-scale freshening as a result of processes including precipitation minus evaporation changes. Thus, unlike previous studies, the freshening is applied as far north as $55^{\circ} \mathrm{S}$, beyond the Antarctic ice margin. It is found that imposing a largescale surface freshening causes a surface cooling and sea ice increase under preindustrial conditions, because of a reduction in ocean convection and weakened entrainment of warm subsurface waters into the surface ocean. This is consistent with intermodel relationships between CMIP5 models and the simulations, suggesting that models with larger surface freshening also exhibit stronger surface cooling and increased sea ice. Additional experiments are conducted with surface salinity restoration applied to capture observed regional salinity trends. Remarkably, without any mechanical wind trend forcing, these simulations accurately represent the spatial pattern of observed surface temperature and sea ice trends around Antarctica. This study highlights the importance of accurately simulating changes in Southern Ocean salinity to capture changes in ocean circulation, sea surface temperature, and sea ice.
\end{abstract}

Supplemental information related to this paper is available at the Journals Online website: https://doi.org/10.1175/JCLI-D-17-0092.s1.

\footnotetext{
${ }^{a}$ Current affiliations: Centre for Southern Hemisphere Oceans Research, Commonwealth Scientific and Industrial Research Organisation Oceans and Atmosphere, Aspendale, Victoria, Australia, and Physical Oceanography Laboratory, Ocean University of China, and Qingdao National Laboratory for Marine Science and Technology, Qingdao, China.
}

Corresponding author: Ariaan Purich, ariaan.purich@csiro.au 


\section{Introduction}

Observed Southern Ocean changes over recent decades include a surface freshening (Durack and Wijffels 2010; Durack et al. 2012; de Lavergne et al. 2014), surface cooling (Fan et al. 2014; Marshall et al. 2014; Armour et al. 2016; Purich et al. 2016a), and circumpolar increase in Antarctic sea ice (Cavalieri and Parkinson 2008; Comiso and Nishio 2008; Parkinson and Cavalieri 2012). Various explanations for the increase in Antarctic sea ice extent (SIE) seen since regular satellite observations began in 1979, which has occurred despite global warming over this period, have been proposed (Hobbs et al. 2016). These include natural variability (Mahlstein et al. 2013; Polvani and Smith 2013; Zunz et al. 2013; Li et al. 2014; Simpkins et al. 2014; Gagné et al. 2015; Meehl et al. 2016; Purich et al. 2016b), changes in surface winds (Holland and Kwok 2012; Fan et al. 2014; Turner et al. 2009; Li et al. 2014; Simpkins et al. 2014; Purich et al. 2016a), surface freshening as a result of ice sheet and shelf runoff and iceberg fluxes (Bintanja et al. 2013, 2015; Swart and Fyfe 2013; Pauling et al. 2016), and surface freshening as a result of sea ice transport (Haumann et al. 2016).

Surface freshening can act to increase sea ice coverage by increasing surface stratification, reducing convective mixing of warmer subsurface waters, and causing a surface cooling (e.g., Marsland and Wolff 2001; Liu and Curry 2010; de Lavergne et al. 2014; Morrison et al. 2015). Early model studies of the influence of surface freshening on Antarctic sea ice found freshening to be associated with an increase in ice coverage in ocean-ice models (Marsland and Wolff 2001; Beckmann and Goosse 2003; Hellmer 2004; Aiken and England 2008). However, more recent studies using global coupled climate models with additional freshwater applied around the Antarctic margins to simulate increased ice sheet melt and runoff have found conflicting results: Bintanja et al. $(2013,2015)$ found that the increased freshwater has likely contributed to the increase in Antarctic SIE, whereas Swart and Fyfe (2013) found the influence to be small and not able to explain the observed sea ice changes. Pauling et al. (2016) also found that applying an extra freshwater flux around the continental margins was insufficient to offset anthropogenic forcing. Zunz and Goosse (2015) found that the inclusion of an additional freshwater flux in simulations with data assimilation improves the reconstruction of sea ice trends; however, it does not seem to be required to obtain an increase in sea ice extent in hindcast simulations. Additionally, Kirkman and Bitz (2011) found that under global warming conditions, increased melting of sea ice leads to surface freshening, which in turn leads to surface cooling of the Southern Ocean.
Previous studies (Bintanja et al. 2013, 2015; Swart and Fyfe 2013; Pauling et al. 2016) focused on runoff from the Antarctic ice sheet and shelf melt as the source of freshwater to the Southern Ocean, in part motivated by the fact that models participating in phase 5 of the Coupled Model Intercomparison Project (CMIP5) explicitly exclude such melt contributions. However, Pauling et al. (2016) found that the CMIP5 models happen to simulate runoff changes resulting from precipitation changes over Antarctica that are approximately the same as estimated land-ice melt and ice-shelf melt rates. Further, the largest source of freshwater to the Southern Ocean is the precipitation minus evaporation $(P-E)$ falling directly onto the ocean (Pauling et al. 2016). Increased $P-E$ leads to stronger stratification and a reduction in oceanic vertical heat transfer, and thus to increased sea ice (Martinson 1990; Marsland and Wolff 2001; Goosse and Zunz 2014). Observational estimates of $P-E$ over the Southern Ocean are highly uncertain: there are no direct measurements of precipitation over the ocean and satellite estimates provide only a snapshot in time based on the time of the scan (e.g., Trenberth et al. 2017), while evaporation is estimated from bulk formula with many uncertain inputs, leading to considerable imbalances in global surface flux estimates (e.g., Josey et al. 2013). As such, there is a large spread in observational products and reanalysis (Fig. 1). A detailed assessment of $P-E$ trends in various reanalyses since 1989 found no robust widespread precipitation trends over the sea ice region, and a large disagreement between different reanalyses (Bromwich et al. 2011). However, most estimates suggest that there has been an increase in precipitation and $P-E$ over the Southern Ocean south of $50^{\circ} \mathrm{S}$ since 1979 (Fig. 1), and this is consistent with the multidecadal broad-scale freshening that has been reported in numerous independent studies (Durack and Wijffels 2010; Helm et al. 2010; de Lavergne et al. 2014; Haumann et al. 2016).

Measurements of surface salinity provide an integrated view of freshwater input changes, and the surface freshening seen since 1950 (Fig. 1a; Durack and Wijffels 2010; de Lavergne et al. 2014), along with interior freshening (e.g., Wong et al. 1999), further suggest that there has been an increase in broad-scale freshwater input, likely including an increase in $P-E$ over the Southern Ocean (e.g., Durack et al. 2012; de Lavergne et al. 2014). This increase is also in agreement with the positive trend in the southern annular mode (SAM) observed over the latter half of the twentieth century (Marshall 2003), associated with a poleward shift and intensification in the extratropical westerly wind jet and storm tracks (e.g., Thompson and Solomon 2002; Fyfe 2003; Frederiksen and Frederiksen 2007). These SAM changes have previously 
(a) SSS trends (PSU $(10 \mathrm{y})^{-1}$ )

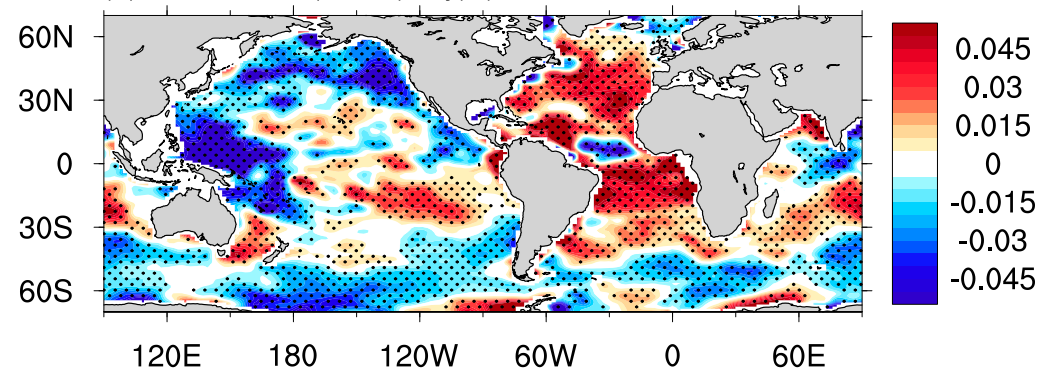

(b) SSS trends

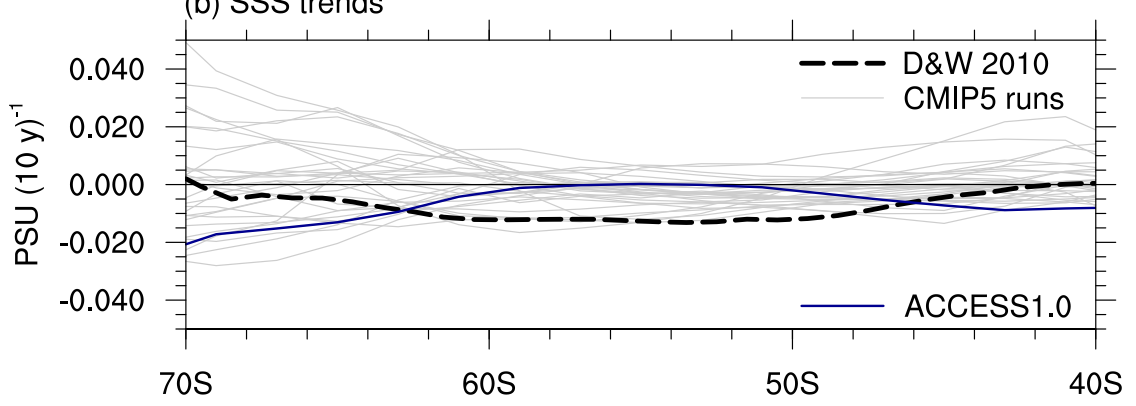

(c) P trends

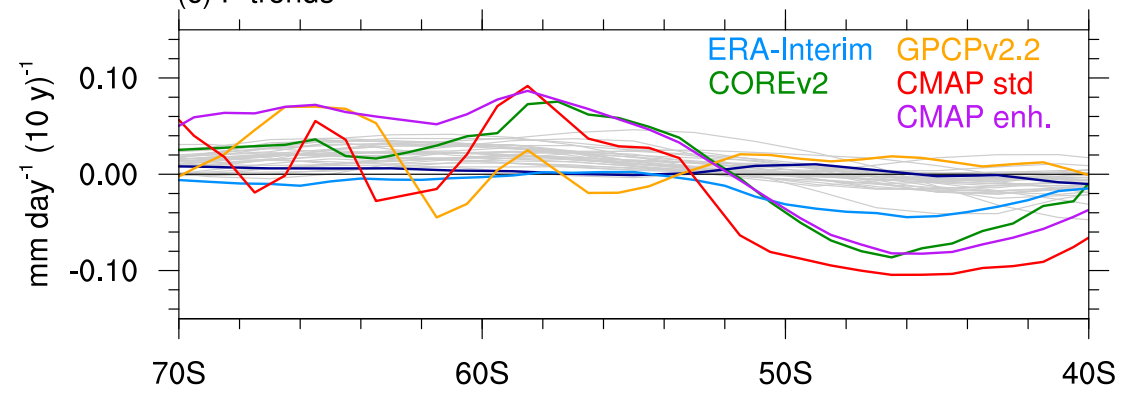

(d) P-E trends

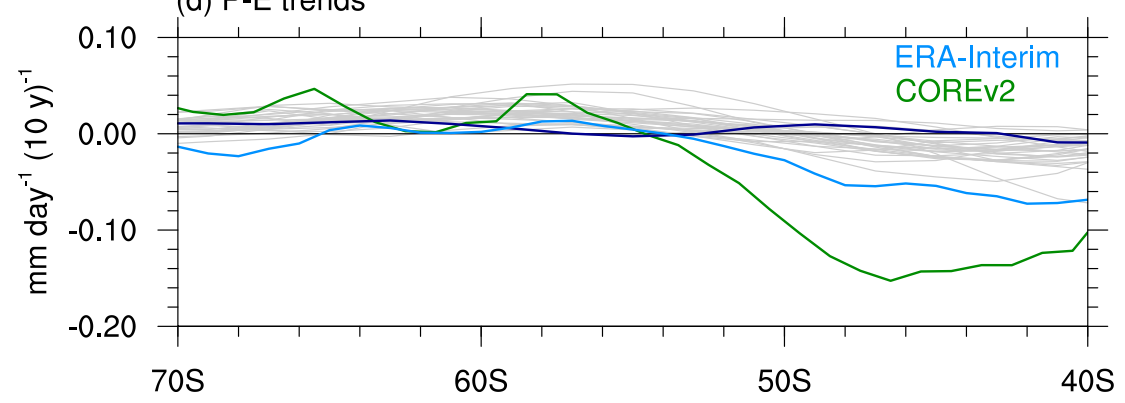

FIG. 1. Trends over 1950-2000: (a) observed SSS trends from Durack and Wijffels (2010); (b) zonal-mean SSS trends for observations (Durack and Wijffels 2010) and CMIP5 models; (c) zonal-mean precipitation trends for observations (ERA-Interim, COREv2, GPCPv2.2, CMAP standard, and CMAP enhanced) and CMIP5 models; and (d) zonal-mean $P-E$ trends for observations (ERA-Interim and COREv2) and CMIP5 models. In (a), stippling indicates significance at the $95 \%$ level. In (b), observations are shown with a dashed black line. In (c),(d), observations are shown with colored lines and vary in the time periods they cover (refer to section 2). In (b)-(d), CMIP5 models are shown with gray lines, and the ACCESS1.0 CMIP5 run is shown with a dark blue line. 
been suggested to increase precipitation over the highlatitude Southern Ocean (while decreasing precipitation in midlatitudes; e.g., Son et al. 2009), with less influence on evaporation (Purich and Son 2012), thus enhancing total $P-E$ over a broad region of the high-latitude Southern Ocean (including well north of the sea ice margin). The goal of this study is to better understand the role of this broad-scale freshening of the surface Southern Ocean on both surface cooling and Antarctic sea ice trends.

Further, while CMIP5 models capture the observed sign of the recent SAM trend, they tend to underestimate its strength, and the trend in the westerly wind jet (Swart and Fyfe 2012; Wilcox et al. 2012; Bracegirdle et al. 2013; Mahlstein et al. 2013; Purich et al. 2013). The CMIP5 models also either underestimate or fail to capture the surface freshening seen in observations over 1950-2000 between $50^{\circ}$ and $60^{\circ} \mathrm{S}$ : of the models that exhibit surface freshening, all underestimate the strength of the observed freshening, and only five models are within the observational uncertainty range (Figs. 1b and 2; Durack 2015). That is, 26 out of 31 CMIP5 models assessed in this study show sea surface salinity (SSS) trends over $50^{\circ}-60^{\circ} \mathrm{S}$ that are inconsistent with the observed freshening (Fig. 2). When multiple realizations per model are considered, 60 out of 68 CMIP5 realizations show SSS trends that are inconsistent with the observed freshening (Fig. S1 in the supplemental material). This is likely due to model precipitation and cloud biases; however, uncertainty in observed $P-E$ makes it difficult to assess the extent to which models underestimate changes in precipitation (Fig. 1c) and $P-E$ (Fig. 1d). Internal variability may also play a role in contributing to the observed trend. In any case, Fig. $1 \mathrm{~b}$ indicates that for almost all cases, the model's simulation of the recent multidecadal surface freshening is weaker than observed. In addition to precipitation biases, a component of the SSS freshening could be due to increased ice shelf melt, land-ice melt, or an increase in northward sea ice advection and melt. It is thus difficult to fully separate the processes that might be biased in CMIP5 models. Either way, as high-latitude surface freshening is associated with surface cooling and a sea ice increase, this may be another factor contributing to the CMIP5 models' excessive Southern Ocean surface warming contrasting with the observed surface cooling (Marshall et al. 2014; Purich et al. 2016a) and sea ice decline contrasting with the observed increases (Mahlstein et al. 2013; Polvani and Smith 2013; Swart and Fyfe 2013; Turner et al. 2013; Zunz et al. 2013; Gagné et al. 2015) over recent decades. Understanding whether an underestimated broad-scale freshening may have contributed to the differences between observed and CMIP5 trends provides further motivation for investigating the role of broad-scale freshening in driving Southern Ocean surface changes.
In this study we perform experiments using the Australian Community Climate and Earth-System Simulator, version 1.0 (ACCESS1.0), a global coupled climate model participating in CMIP5. In a recent CMIP5 assessment this model was found to be one of the best in the suite for simulating regional distribution and extent of Antarctic sea ice (Ivanova et al. 2016). We apply an idealized freshwater flux over the high-latitude Southern Ocean between $55^{\circ}$ and $70^{\circ} \mathrm{S}$, with the aim of achieving a SSS trend similar in magnitude to the Durack and Wijffels (2010) trend. The sea surface temperature (SST) and sea ice responses to the broadscale freshwater input are examined and the regional pattern of changes and sea ice feedbacks are discussed. We also make a comparison with CMIP5 output. Our results suggest that recent multidecadal trends in largescale surface salinity over the Southern Ocean have played a role in the observed surface cooling seen in this region. In addition, our simulations suggest that the underestimation of observed surface freshening by CMIP5 models is an important factor contributing to the SST warming and Antarctic sea ice decline seen in almost all CMIP5 models, at odds with observed trends. While diagnosed as an important factor here, we find that a uniform freshening alone cannot fully account for the model-observation differences. Other factors, such as decadal variability (Li et al. 2014; Simpkins et al. 2014; Meehl et al. 2016; Purich et al. 2016b), responses to greenhouse gas forcing (Armour et al. 2016) and stratospheric ozone forcing (Turner et al. 2009), and wind forcing effects (Holland and Kwok 2012; Fan et al. 2014; Purich et al. 2016a) are likely also important.

\section{Data and methods}

\section{a. Model description}

The ACCESS1.0 model is a fully coupled global climate model, developed by the Commonwealth Scientific and Industrial Research Organisation and the Australian Bureau of Meteorology (Bi et al. 2013b). It is built by coupling the United Kingdom Met Office atmospheric Unified Model (UM; Davies et al. 2005; Martin et al. 2010, 2011) to the Geophysical Fluid Dynamics Laboratory Modular Ocean Model, version 4.1 (MOM4.1; Griffies et al. 2010), and the Los Alamos National Laboratory sea ice model, version 4.1 (CICE4.1; Hunke and Lipscomb 2010), as described in Bi et al. (2013a). These model components are coupled using the Centre Européen de Recherche et de Formation Avancée en Calcul Scientifique Ocean Atmosphere Sea Ice Soil, version 3.2 (OASIS3.2; Valcke 2006), coupling framework. ACCESS1.0 is configured 


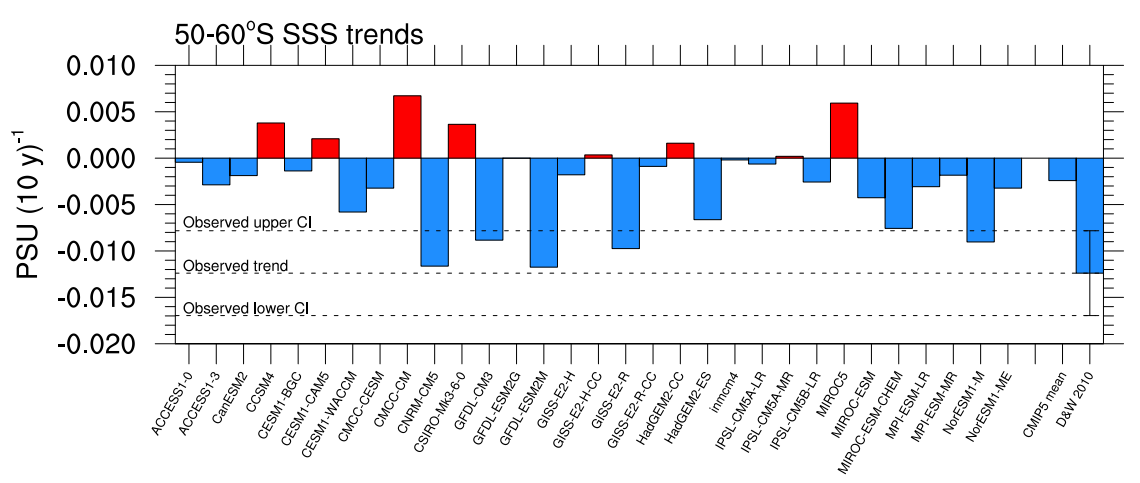

FIG. 2. Trends in SSS over $1950-2000$, area averaged over $50^{\circ}-60^{\circ} \mathrm{S}$. The first available realization for each CMIP5 model is shown, along with the CMIP5 multimodel mean and the Durack and Wijffels (2010) observational estimate. Error bars show the approximate 95\% confidence estimates of the observed trend, and horizontal dashed lines are included for comparison between the CMIP5 trends and observations.

with the Met Office Hadley Centre Global Environment Model, version 2 (HadGEM2, r1.1) atmospheric physics and the Met Office Surface Exchange Scheme land surface model, version 2. The atmospheric component of the model used here has a Gaussian N96 horizontal resolution of approximately $1.25^{\circ}$ latitude $\times 1.875^{\circ}$ longitude and 38 vertical levels. The ACCESS1.0 configuration of MOM4.1 and CICE4.1 has 360 longitude $\times 300$ latitude grid points on a logically rectangular grid with enhanced resolution at the equator and 50 vertical levels with $10-\mathrm{m}$ resolution in the upper $200 \mathrm{~m}$ (Bi et al. 2013b).

\section{b. Experimental design}

Using ACCESS1.0 in fully coupled configuration, simulations with an additional freshwater flux into the ocean component are branched from a preindustrial control (piControl) run. We refer to these as the freshwater simulations. Freshwater simulations have the same forcings as for the ACCESS1.0 CMIP5 piControl run, including preindustrial atmospheric concentrations of $\mathrm{CO}_{2}, \mathrm{CH}_{4}, \mathrm{~N}_{2} \mathrm{O}$, and $\mathrm{O}_{3}$, the solar constant, aerosol emissions, seasonally varying biogenic aerosol concentrations, and a background $\mathrm{SO}_{2}$ outgassing flux, but with the stratosphere clear of volcanic aerosols (Bi et al. 2013b; Dix et al. 2013). This experimental design was chosen rather than including historical and future scenario forcings to isolate the influence of Southern Ocean surface freshening on the climate system from other confounding factors. Five ensemble members are branched from different years of the piControl run, each five years apart, and run for 50 years. We consider the five-member ensemble to investigate the role of unforced variability on these relatively short simulations.

Our aim is to simulate a clear freshening signal of similar magnitude to the broad-scale freshening of the Durack and Wijffels (2010) SSS trend that will allow an investigation into the influence of this observed surface freshening on regional hydrography and circulation. We are not initially trying to replicate the observed SSS trend exactly (although later on we consider SSS restoring experiments that match the observed geographic distribution), but rather use an idealized freshwater forcing to obtain freshening trends of approximately comparable magnitude. To achieve this, an identical freshwater flux is added to each ensemble member as an additional $P-E$ flux into the ocean model component over $55^{\circ}-70^{\circ} \mathrm{S}$, while the atmosphere, sea ice, and ocean are able to freely evolve to this additional flux. The additional $P-E$ flux is applied as a $P-E$ flux correction, to augment the $P-E$ flux received due to atmospheric processes, rather than by prescribing the total $P-E$. This yields a surface freshening trend under otherwise piControl conditions. The added freshwater flux is constant over $55^{\circ}-70^{\circ} \mathrm{S}$, and zero elsewhere, and increases by a constant amount each year, representing an annually increasing linear trend in $P-E$. Because of model sensitivity assessed in short tests, a freshwater flux trend of $0.1 \mathrm{~mm} \mathrm{day}^{-1}(10 \mathrm{yr})^{-1}$ is applied, which yields a clear freshening signal as desired (Fig. 3b). This is considerably larger than the $P-E$ trend simulated by the CMIP5 models as shown in Fig. 1d.

\section{c. Observational and CMIP5 datasets}

We compare output from the ACCESS1.0 freshwater simulations to various observationally based datasets. For surface and subsurface salinity, we utilize trends from Durack and Wijffels (2010), calculated for 19502000. We also utilize potential temperature trends from Durack and Wijffels (2010). For surface trends over 1979-2013 we use SST from the Hadley Centre Sea Ice and Sea Surface Temperature dataset (HadISST; Rayner et al. 2003; http://www.metoffice.gov.uk/hadobs/hadisst/) 
(a) D\&W 2010 SSS trends (PSU $\left.(10 \mathrm{y})^{-1}\right)$
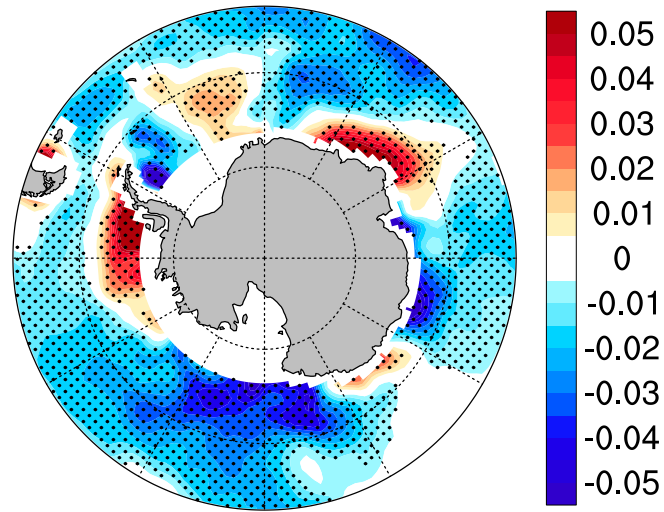

(c) HadISST SST trends $\left({ }^{\circ} \mathrm{C}(10 \mathrm{y})^{-1}\right)$
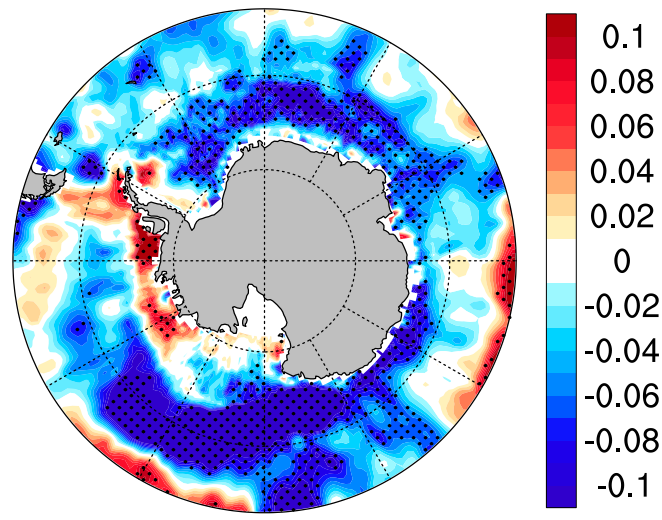

(e) NSIDC Bootstrap SIC trends $\left(\%(10 y)^{-1}\right)$
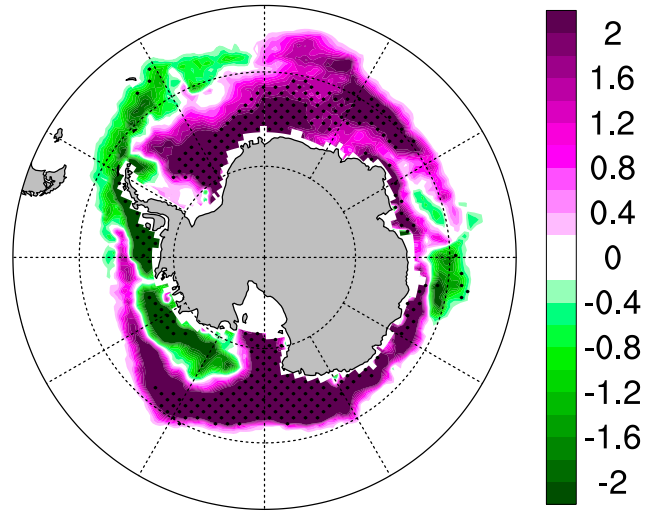

(b) ACCESS1.0 SSS trends (PSU $(10 \mathrm{y})^{-1}$ )

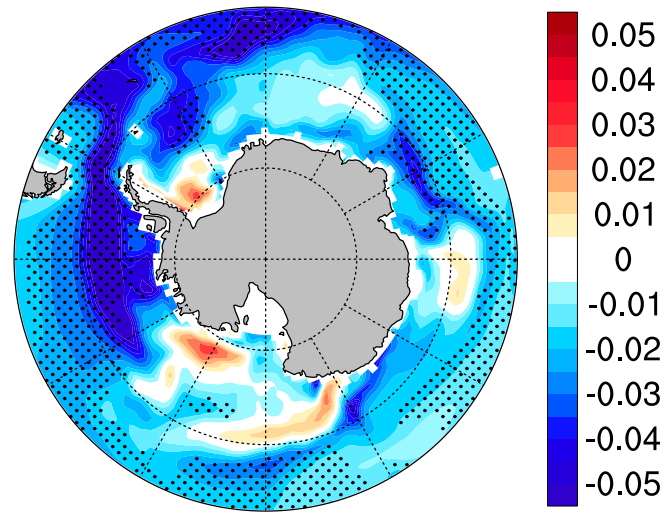

(d) ACCESS1.0 SST trends $\left({ }^{\circ} \mathrm{C}(10 \mathrm{y})^{-1}\right)$

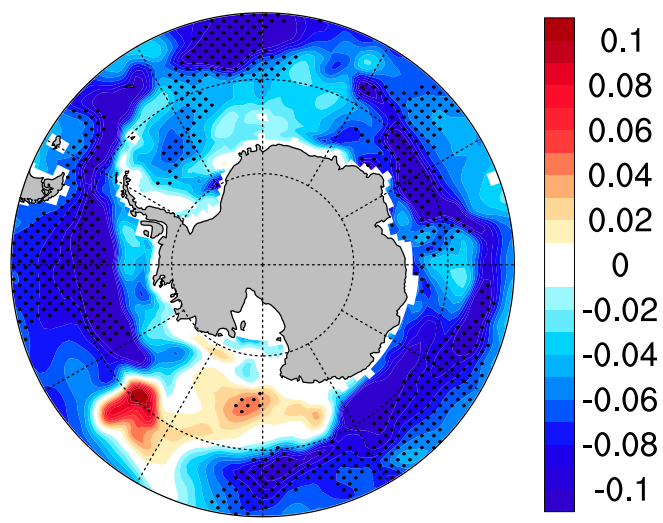

(f) ACCESS1.0 SIC trends $\left(\%(10 \mathrm{y})^{-1}\right)$

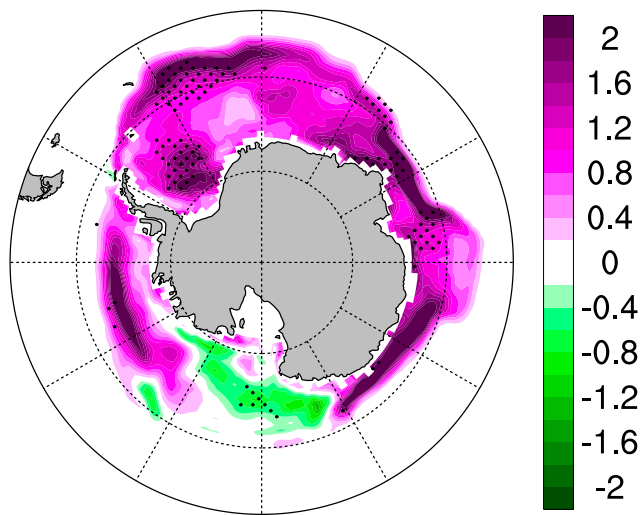

FIG. 3. (left) Observed and (right) ensemble-mean 50-yr trends from the ACCESS1.0 freshwater simulations: (a),(b) SSS trends, (c),(d) SST trends, and (e),(f) SIC trends. In all panels, stippling indicates trend significance at the $95 \%$ level. Observations are from Durack and Wijffels (2010) (1950-2000) in (a), HadISST (1979-2013) in (c), and NSIDC bootstrap (1979-2013) in (e).

and passive microwave sea ice concentration (SIC) processed using the National Snow and Ice Data Center (NSIDC) bootstrap algorithm (Comiso and Nishio 2008; Meier et al. 2015). For area-averaged SIE we make use of the NSIDC SIE index (Fetterer et al. 2002). We note that there is an inconsistency in the time periods of the different observational datasets assessed here. Continuous observations of Antarctic sea ice are limited to the 
satellite period 1979-2013 and one of the motivations of this research is to better understand the drivers of Antarctic sea ice trends over this time. While HadISST extends back far earlier than 1979, analyzing the same period as for sea ice is useful in understanding how SST and sea ice trends are related. This also has the added benefit of using the temporal period where satellite data coverage provides the dominant measurement inputs for HadISST. Unfortunately, observations of SSS and subsurface fields are severely limited, and although shorter period trend estimates do exist (e.g., over 1970-2004 Durack et al. 2014), error estimates increase markedly, as the primary limitation in Southern Hemisphere trends is a lack of data. Over shorter time periods interannualdecadal variability also dominates, whereas over longer periods such as 1950-2000, trends are more coherent and physically interpretable. Based on this limitation, despite not aligning with the satellite-measured sea ice and SST period, we choose to assess the 1950-2000 SSS and subsurface trends. Changes over the various periods are all scaled to show the trend per decade, to allow for an easier comparison across the differing time scales of the products analyzed.

Data sparsity is a considerable challenge when assessing the pre-Argo period for global ocean temperature and salinity changes, and is a particular problem in the sparsely sampled Southern Hemisphere. Durack and Wijffels (2010) discuss the issue of data sparsity and provide uncertainty estimates for the presented trend results. Table 1 in Durack and Wijffels (2010) also includes error estimates for regional comparisons to other published literature. We note that other studies that have assessed trends in salinity have also attempted to provide uncertainty estimates: the Durack and Wijffels (2010) analysis is one of at least five studies (see also Boyer et al. 2005; Hosoda et al. 2009; Helm et al. 2010; Skliris et al. 2014) that have assessed salinity changes for the global ocean. Each of these studies reports a considerable broadscale freshening for the Southern Ocean. A recent Southern Ocean regionally focused study by de Lavergne et al. (2014) has reproduced the freshening patterns using very different methodologies to previous studies (see their Fig. 2), strongly suggesting that the Southern Ocean surface freshening is a real observed feature, with the obvious caveat that all observed estimates are limited by measurements.

To support our findings based on the Durack and Wijffels (2010) dataset, we undertook a parallel analysis using the EN4.2.0 dataset (Good et al. 2013; see also Fig. S2 in the supplemental material). The EN4.2.0 dataset is not optimized for trend calculation (rather the dataset is focused on "reconstructing" each month of the ocean state from 1900 to 2017), and therefore is highly sensitive to data sparsity and "zero anomalies."
However, when we contrast the same period analyzed in Durack and Wijffels (2010), we get similar spatial patterns for the key features we are assessing (e.g., broadscale freshening south of $50^{\circ} \mathrm{S}$ but with increased salinity in the Bellingshausen and eastern Amundsen Seas, part of the Weddell Sea, the Cosmonauts Sea, and around $140^{\circ} \mathrm{E}$ ), although with smaller magnitudes.

As mentioned above, observational estimates of $P-E$ over the Southern Ocean are highly uncertain (e.g., Josey et al. 2013; Bromwich et al. 2011). We compare various precipitation and evaporation datasets, including Global Precipitation Climatology Project, version 2.2 (GPCPv2.2), precipitation over 1979-2013 (Adler et al. 2003), CPC Merged Analysis of Precipitation (CMAP) standard and enhanced precipitation over 1979-2013 (Xie and Arkin 1997), ERA-Interim precipitation and evaporation over 1979-2013 (Dee et al. 2011), and Co-ordinated Ocean-Ice Reference Experiments, version 2 (COREv2), precipitation and evaporation over 1979-2006 (Large and Yeager 2009). We do not include the National Centers for Environmental Prediction (NCEP)-National Center for Atmospheric Research (NCAR) reanalysis precipitation and evaporation, as this reanalysis is already incorporated in the CMAP enhanced precipitation product, and in the COREv2 fields. We emphasize the limitations with observational precipitation and evaporation products over the Southern Ocean, as discussed in the introduction, and as such rely on surface salinity to provide an integrated view of freshwater input changes.

CMIP5 data from 31 models with a total of 68 runs are also analyzed (see Table S1 in the supplemental material for a list of models). All models with required variables available (SSS, SST, SIC, potential temperature, precipitation, and evaporation) for the historical experiment over 1950-2005 and the representative concentration pathway 8.5 (RCP8.5; high emission scenario) experiment over 2006-13 are included in the analysis. As all scenarios have similar forcings over 2006-13, the choice of RCP8.5 is arbitrary.

\section{d. Data analysis}

Prior to analysis all ACCESS1.0 and observational data are bilinearly regridded to a $1^{\circ} \times 1^{\circ}$ grid. Because of the large amount of data dealing with the CMIP5 ensemble, CMIP5 data are bilinearly regridded to a $2^{\circ} \times 2^{\circ}$ grid. Annual and seasonal averages are then calculated.

Gridpoint linear trends of surface fields are calculated. The significance of observed trends is determined using the two-sided Student's $t$ test at the 95\% confidence level. Autocorrelation was accounted for by defining the effective sample size $N_{\text {eff }}$ as follows: 


$$
N_{\text {eff }}=N\left(\frac{1-r_{1}}{1+r_{1}}\right),
$$

where $N$ is the sample size, and $r_{1}$ is the lag- 1 autocorrelation of the detrended time series of interest (Simpkins et al. 2012). Note that gridpoint SSS trends and an estimate of error are provided directly from Durack and Wijffels (2010) and are simply area averaged here, and that the different observational products vary in the time periods for which they are available. Ensemble mean trends for the freshwater simulations are calculated by taking the linear trend in each 50-yr simulation, dedrifting by removing the linear trend in the piControl for the corresponding 50-yr period (e.g., Sen Gupta et al. 2013), and then averaging across the five simulations. Significance of ensemble mean trends is determined when the absolute value of the ensemble mean trend is greater than two standard deviations of the intermember spread ( $\sim 95 \%$ confidence level).

Zonal mean linear trends of subsurface fields are calculated by first taking the three-dimensional trends and then averaging zonally. Salinity and potential temperature trends provided by Durack and Wijffels (2010) are simply averaged zonally. Note that the significance of these observed trends is also averaged zonally, and so should be considered as a guide only. As for the surface fields, 50-yr trends for individual ensemble members are first calculated, and then dedrifted by removing the zonal-mean trend in the piControl for the corresponding 50-yr period. Dedrifted trends are then averaged to determine the ensemble mean trend. Significance is determined when the absolute value of the ensemble mean trend is greater than two standard deviations of the intermember spread ( $\sim 95 \%$ confidence level).

Zonal mean trends are calculated for the CMIP5 models over 1950-2000. However, for area-averaged metrics we consider trends over 1979-2013, for comparison with satellite-based observational estimates of SST (HadISST) and SIC (NSIDC bootstrap). Areaaveraged SSS and SST are calculated over $55^{\circ}-70^{\circ} \mathrm{S}$ and SIE is calculated as the total area where SIC exceeds $15 \%$. Comparable metrics are calculated for the observational products, and for the freshwater simulations.

\section{Results}

\section{a. Freshwater simulations}

Observed and ensemble mean trend maps are shown in Fig. 3, displaying the regional patterns of trends. The Durack and Wijffels (2010) SSS trends (Fig. 3a) show substantial freshening over the Southern Ocean, although there is a notable increase in surface salinity in the Bellingshausen Sea. HadISST cooling (Fig. 3c) is seen in all regions, except near the coast in the Amundsen and Bellingshausen Seas, where a significant warming is seen. Except for a region of increased salinity off east Antarctica and a weak increase in the Weddell Sea, the regions of cooling tend to align well with the regions of freshening, and vice versa, despite comparing the Durack and Wijffels (2010) and HadISST datasets over different periods for the reasons outlined in the data and methods section. These two trend maps (Figs. 3a,c) have an uncentered pattern correlation coefficient of $r=0.50$ (see also Fig. S3 in the supplemental material). Sea ice changes largely mirror SST changes (Fig. 3e), with increased SIC in most regions around Antarctica, but decreased SIC in the Amundsen and Bellingshausen Seas, and in the outer Weddell Sea.

The broad-scale trends seen in the observations are also captured in the freshwater simulations: applying an idealized increased freshwater flux into the ocean causes an SSS freshening (Fig. 3b), increasing the surface stability. All ensemble members simulate a freshening trend in SSS over $50^{\circ}-70^{\circ} \mathrm{S}$ in response to the applied freshwater flux, although it is worth noting that the simulated zonal-mean freshening in response to the applied $P-E$ flux is stronger than the observed freshening. The increased stability reduces convective overturning, resulting in less entrainment of heat into the mixed layer, and can also result in reduced upward vertical isopycnal heat transport (Gregory 2000; Kirkman and Bitz 2011). In response to the surface freshening, all ensemble members also show a broad-scale surface cooling, accompanied by increased sea ice coverage occurs in most regions (Figs. 3d,f). As for the observations, there is a strong relationship between regions of freshening (Fig. 3b) and cooling (Fig. 3d) in the freshwater simulations, with these two trend maps having an uncentered pattern correlation of $r=0.86$ (see also Fig. S3).

Zonal-mean trend patterns in simulated salinity (Fig. 4b) and potential temperature (Fig. 5b) reveal a high-latitude freshening and cooling of the surface layer, with warming below (discussed further below). These patterns indicate a reduction in cool season convective overturning between approximately $60^{\circ}$ and $70^{\circ} \mathrm{S}$ (Fig. 5b) as a result of increased surface stability, with less entrainment of warmer subsurface waters to the surface ocean when convection is reduced. Similar to Kirkman and Bitz (2011), we also assess trends in water age, which acts as a tracer in ACCESS1.0 and indicates the length of time since a parcel of water has been at the surface. Regional agreement between areas of subsurface warming and increased water age ${ }^{1}$ (Fig. 6) provides further indication that

\footnotetext{
${ }^{1}$ The uncentered pattern correlation coefficients between potential temperature and water age increase with depth from $r=0.01$ at $55 \mathrm{~m}$ to $r=0.46$ at $537 \mathrm{~m}$ and $r=0.92$ at $2183 \mathrm{~m}$ (see also Fig. S4 in the supplemental material).
} 
(a) D\&W 2010 salinity trends (PSU $(10 \mathrm{y})^{-1}$ )

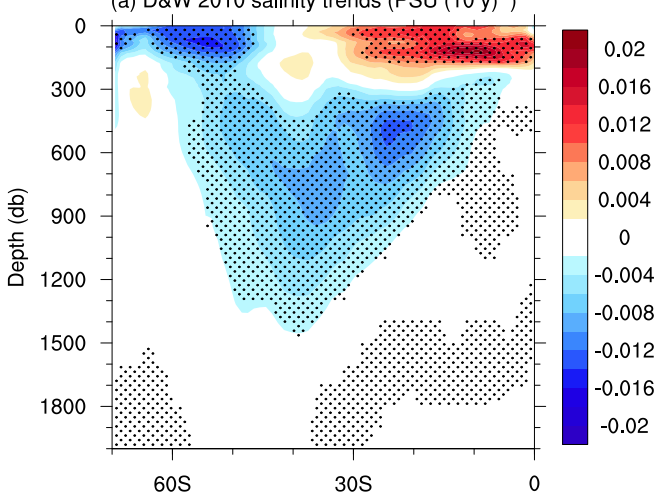

(c) CMIP5 salinity trends (PSU $\left.(10 \mathrm{y})^{-1}\right)$

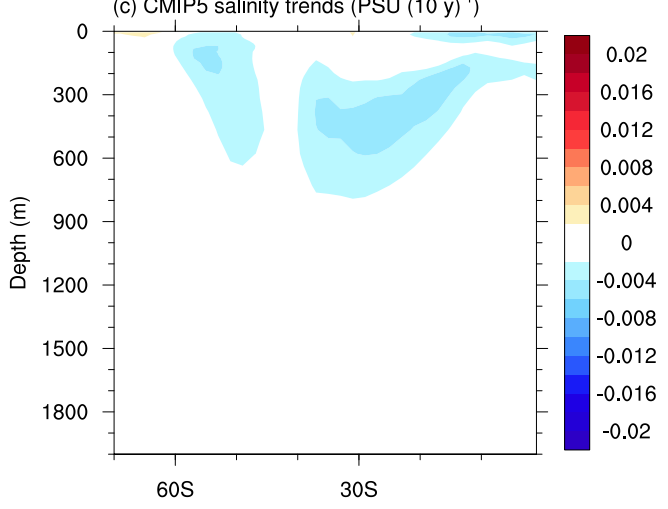

(b) ACCESS1.0 salinity trends (PSU $(10 \mathrm{y})^{-1}$ )

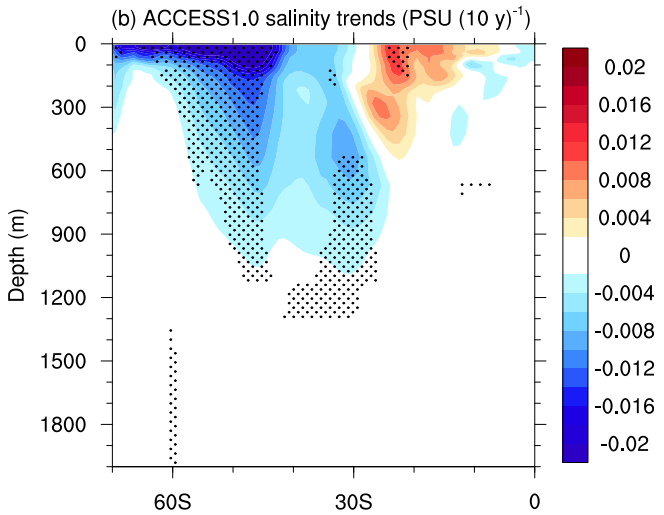

(d) ACCESS1.0 + CMIP5 salinity trends (PSU $(10 \mathrm{y})^{-1}$ )

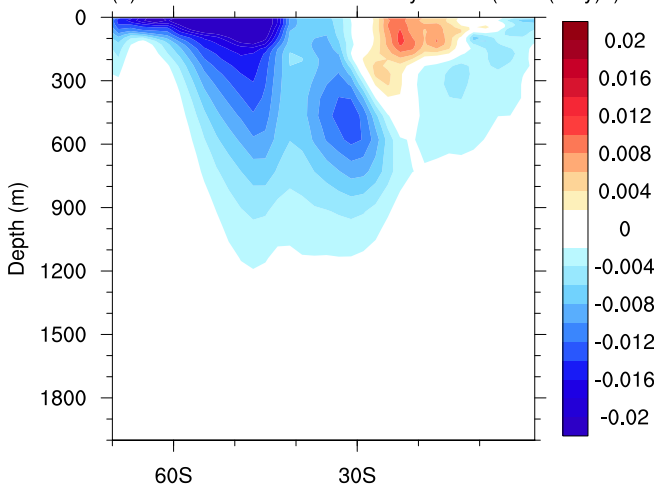

FIG. 4. Zonal-mean 50-yr salinity trends: (a) observed salinity trends from Durack and Wijffels (2010); (b) ensemble-mean trends from the ACCESS1.0 freshwater simulations; (c) CMIP5 multimodel mean trends over 1950-2000; and (d) sum of ACCESS1.0 freshwater ensemble mean trends and CMIP5 multimodel mean trends [i.e., (b) + (c)]. In (a)-(c), stippling indicates trend significance at the $95 \%$ level.

reduced ocean convection is causing the subsurface warming (and accompanying surface cooling), as this would correspond to a decreased input of young water, as also identified in the simulations by Kirkman and Bitz (2011). Along-isopycnal mixing changes may also contribute to the similarities between potential temperature and water age trends in this region (Gregory 2000; Kirkman and Bitz 2011).

Increased total surface heat fluxes into the ocean between $60^{\circ}$ and $70^{\circ} \mathrm{S}$ (Fig. 7a) suggest that the surface heat fluxes largely respond to the SST and sea ice changes, not the other way around. In particular, the heat flux trends are an indicator of increased sea ice and surface cooling in response to the changes in ocean circulation (i.e., less heat is lost to the atmosphere when ice cover is increased, and in ice-free areas more sensible heat is transferred from the atmosphere to the cooler ocean surface; there is also reduced heat loss via outgoing longwave radiation changes). However, between $50^{\circ}$ and $60^{\circ} \mathrm{S}$ there is a weak decrease in the total surface heat flux into the ocean (Fig. 7a). This is likely due to a secondary mechanism related to the reduced ocean convection, whereby a broad-scale shoaling of the mixed layer (Fig. 7b), particularly during austral winter (Fig. 7d), allows more sensible heat loss from the surface during wintertime (Fig. 7c). This leads to a weak decrease in the annual-mean total heat flux into the ocean over $50^{\circ}-60^{\circ} \mathrm{S}$, contributing to the surface cooling in this region.

Despite a zonal-mean freshwater flux being applied in the simulations, regional patterns also emerge. Of particular note, broad significant SSS trends are not seen in the Ross Sea, which may be a result of spurious deep convection simulated by ACCESS1.0 in this region (Fig. 7b; see also de Lavergne et al. 2014), and as a result there is weak (and largely insignificant) warming in this region (Fig. 3d), and a decreasing sea ice trend (a portion of which is significant; Fig. 3f). This contrasts the strong cooling and sea ice growth in the Ross Sea seen in observations (Figs. 3c,e), which have been linked to atmospheric circulation patterns associated with decadal variability (e.g., Meehl et al. 2016; Purich et al. 2016b). A zonal-mean surface freshening and cooling can be seen in all seasons (shown for austral 

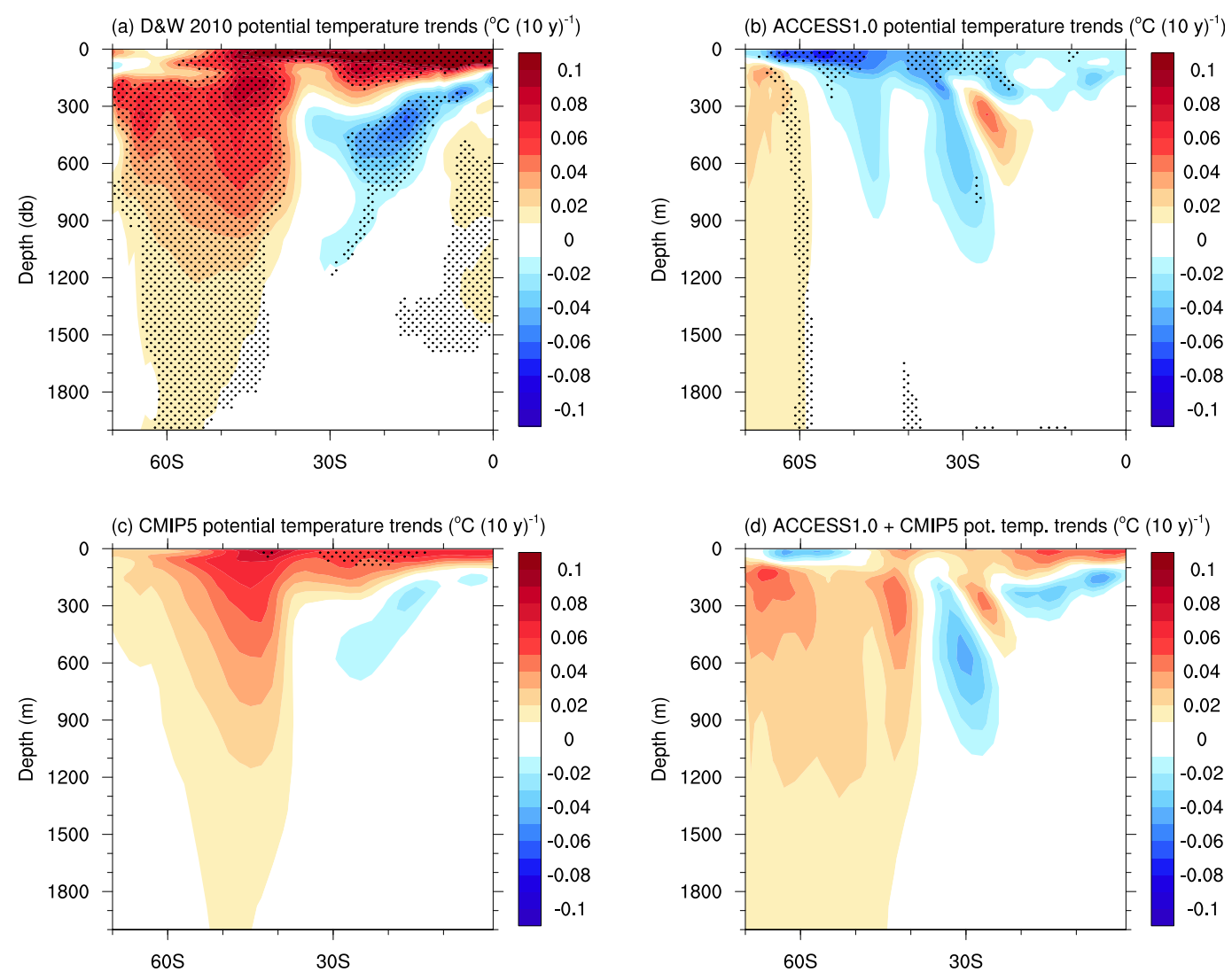

FIG. 5. As in Fig. 4, but for zonal-mean 50-yr potential temperature trends.

summer and winter in Figs. S5 and S6, respectively, in the supplemental material). Sea ice trends respond to the seasonal cycle of growth and retreat, being largest closer to the coast in summer (Fig. S5) and in the outer ice pack in winter (Fig. S6). While a constant freshwater flux is applied into the ocean model component of ACCESS 1.0 over $55^{\circ}-70^{\circ} \mathrm{S}$, the model is free to redistribute this freshwater elsewhere. Over the annual cycle, the additional freshwater input at high latitudes in the model increases SIC, and exports sea ice equatorward where it melts, highlighting the importance of the freshwater redistribution by sea ice, as also discussed in Kirkman and Bitz (2011) and Haumann et al. (2016).

\section{b. Further assessment of subsurface trends}

Given the idealized nature of the applied freshwater forcing simulations, it is far from surprising to see differences between the zonal-mean latitude versus depth salinity trends in observations and the freshwater simulations. The observed freshening (Fig. 4a) is strongest at the surface to $150 \mathrm{~m}$ between $45^{\circ}$ and $70^{\circ} \mathrm{S}$, and extends to $1500-\mathrm{m}$ depth between $30^{\circ}$ and $40^{\circ} \mathrm{S}$, whereas the simulated freshening (Fig. $4 \mathrm{~b}$ ) is strongest at the surface to $150 \mathrm{~m}$ between $40^{\circ}$ and $70^{\circ} \mathrm{S}$. The simulated subsurface freshening does not extend as deep as observed, extending to $1100 \mathrm{~m}$ between $30^{\circ}$ and $40^{\circ} \mathrm{S}$, and does not extend as far equatorward. This could be due to overly strong diffusive mixing of the anomalous lowsalinity waters, a chronic problem in non-eddy-resolving ocean models (England 1993), or because the freshwater simulations do not include surface temperature changes, which have been shown to be important to replicate observed subsurface salinity changes (Lago et al. 2016). Both observations and the freshwater forcing simulations also exhibit a surface salinification north of $30^{\circ} \mathrm{S}$. Salinity increases are stronger and more pervasive in observations than in the freshwater forcing simulations, because the primary drivers of the observed SSS increase relate to a poleward migration of the midlatitude westerly wind jet and storm tracks, which in turn sees precipitation and the northward transport of cool freshwater diminish at this latitude band (e.g., Sen Gupta and England 2006). In contrast, in the freshwater forcing simulations no wind shift is imposed, leaving only the local stratification changes (and any other associated feedbacks) as the major mechanism for surface water mass change. 
(a) $55 \mathrm{~m}$ pot. temp. trends $\left({ }^{\circ} \mathrm{C}(10 \mathrm{y})^{-1}\right)$

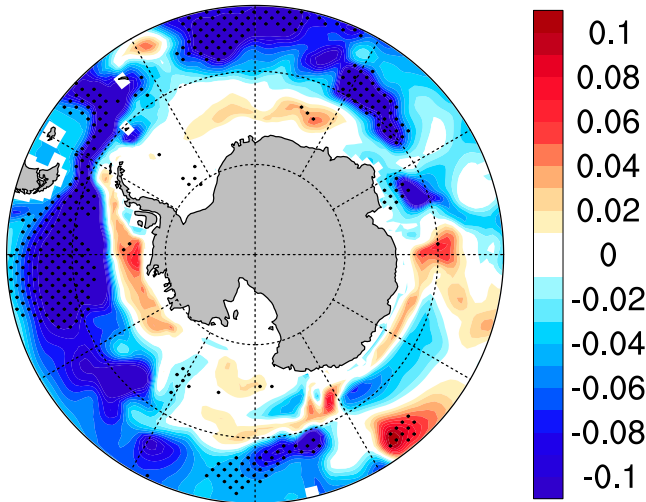

(c) $537 \mathrm{~m}$ pot. temp. trends $\left({ }^{\circ} \mathrm{C}(10 \mathrm{y})^{-1}\right)$

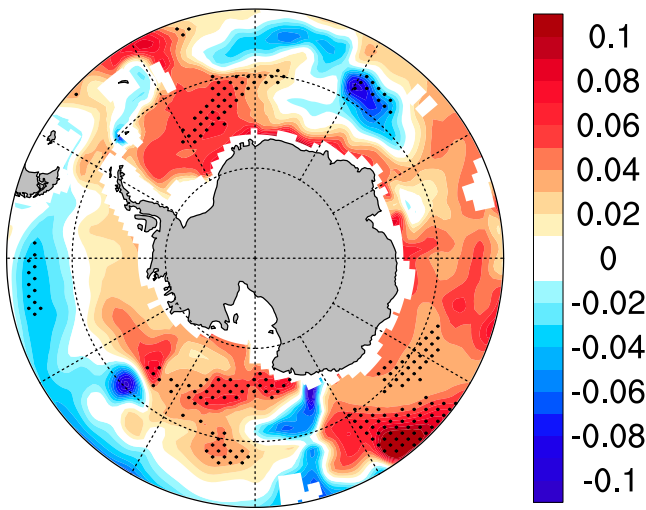

(e) $2183 \mathrm{~m}$ pot. temp. trends $\left({ }^{\circ} \mathrm{C}(10 \mathrm{y})^{-1}\right)$

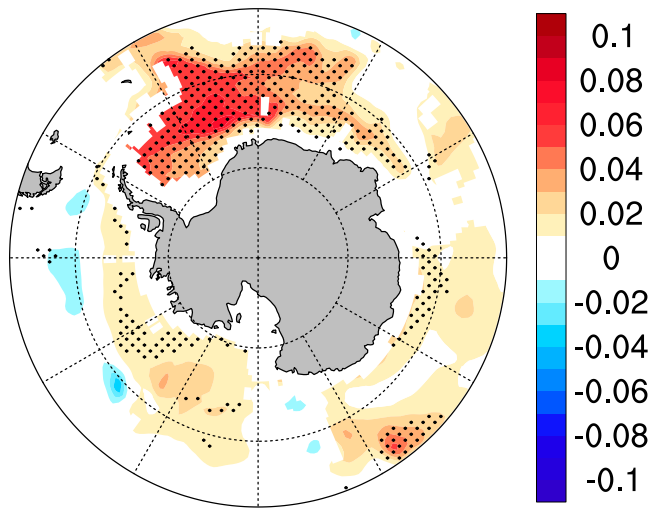

(b) $55 \mathrm{~m}$ water age trends $\left(\mathrm{y}(10 \mathrm{y})^{-1}\right)$

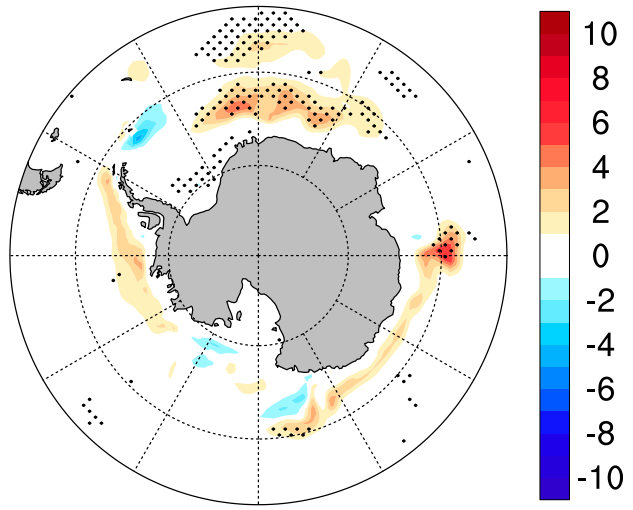

(d) $537 \mathrm{~m}$ water age trends $\left(\mathrm{y}(10 \mathrm{y})^{-1}\right)$

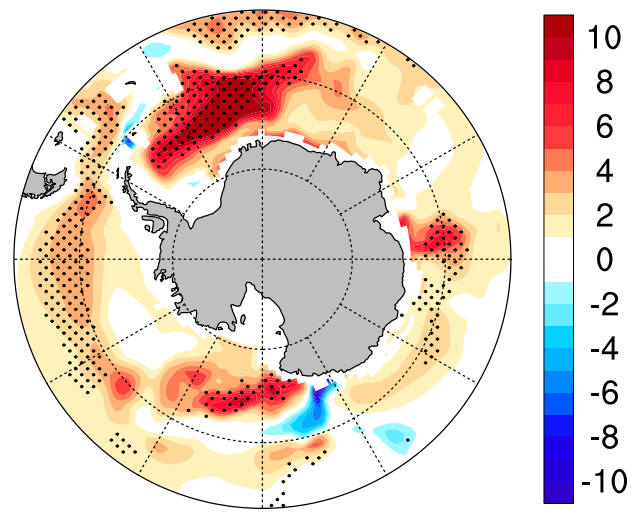

(f) $2183 \mathrm{~m}$ water age trends $\left(\mathrm{y}(10 \mathrm{y})^{-1}\right)$

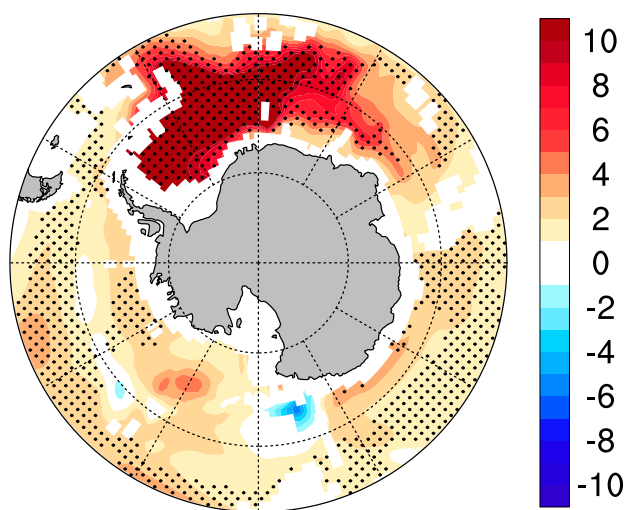

FIG. 6. Ensemble-mean 50-yr trends for (left) potential temperature and (right) water age from the ACCESS1.0 freshwater simulations. Water age acts as a tracer in ACCESS1.0 and indicates the length of time since a parcel of water has been at the surface. Trends are shown for depths of (a),(b) 55, (c),(d) 537, and (e),

(f) $2183 \mathrm{~m}$. In all panels, stippling indicates trend significance at the $95 \%$ level.

The observed trend in potential temperature (Fig. 5a) shows strong warming at the surface for all latitudes (likely driven by greenhouse warming) except between $55^{\circ}$ and $70^{\circ} \mathrm{S}$, where there is an absence of warming.
Warming of the Southern Ocean below $150 \mathrm{~m}$ occurs between $40^{\circ}$ and $70^{\circ} \mathrm{S}$. The freshwater simulations (Fig. 5b) show a surface cooling over the Southern Ocean, strongest between $40^{\circ}$ and $70^{\circ} \mathrm{S}$ to $100 \mathrm{~m}$. 
(a) Annual heat flux into ocean trends

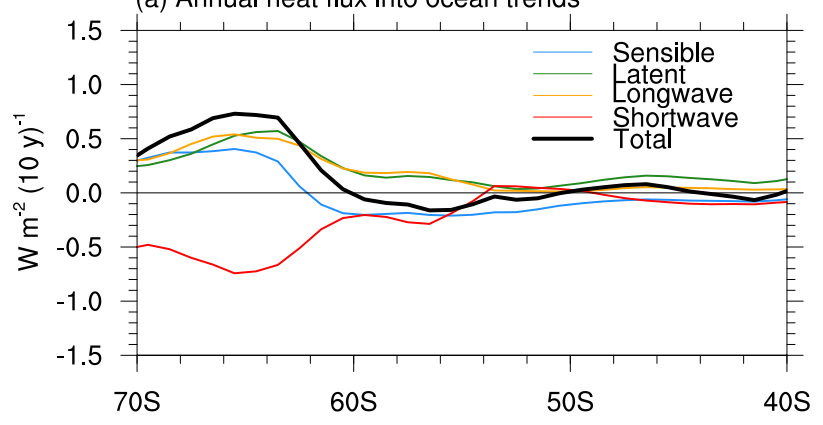

(c) JJA heat flux into ocean trends

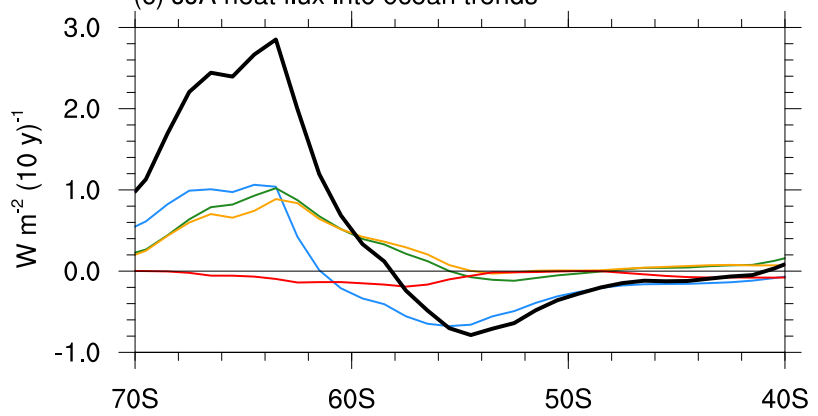

(b) Annual MLD trends (m (10 y $\left.)^{-1}\right)$

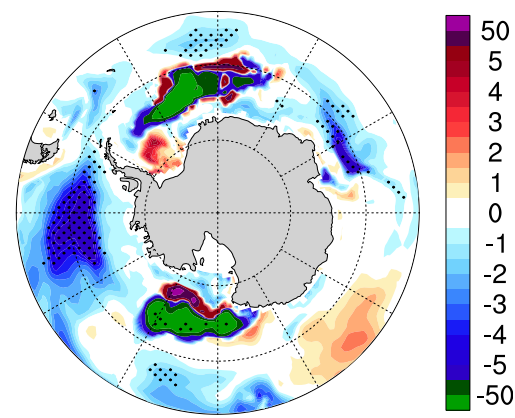

(d) JJA MLD trends $\left(\mathrm{m}(10 \mathrm{y})^{-1}\right)$

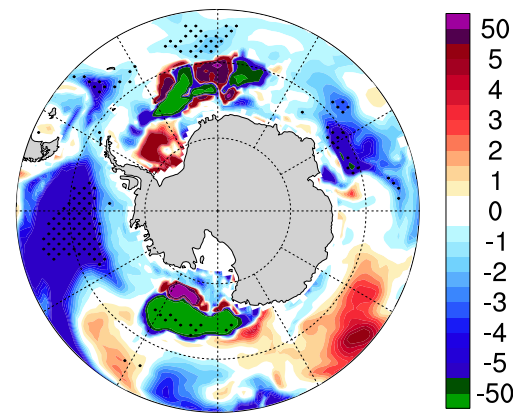

FIG. 7. Ensemble-mean 50-yr trends for (left) zonal-mean surface heat fluxes and (right) mixed layer depth. Trends are shown for (a),(b) the annual mean and (c),(d) austral winter (JJA). In (b),(d), the color bar is nonlinear, with green and purple shading indicating trends in the regions of deep ocean convection, and stippling indicates trend significance at the $95 \%$ level.

Between $60^{\circ}$ and $70^{\circ} \mathrm{S}$ a significant warming signal is seen extending to $3000 \mathrm{~m}$. As discussed above, the simulated salinity and potential temperature signals indicate an increase in surface stability, reducing convective overturning in the Southern Ocean, and thus also the upwelling of warmer subsurface waters, causing a cooling at the surface and warming below (as in, e.g., Martinson 1990; Marsland and Wolff 2001). This surface cooling is then conducive to increased sea ice, as seen in the surface trend map (Fig. 3e).

Despite the differences discussed above, the freshwater simulations capture the observed subsurface salinity pattern much more accurately than the CMIP5 multimodel mean does (Fig. 4c). However, without increased radiative forcing in the freshwater simulations, it is not expected that the simulated potential temperature trends (Fig. 5b) will capture all characteristics of the observed trends (Fig. 5a). For comparison, the potential temperature trends from the CMIP5 multimodel mean are shown in Fig. 5c. This panel represents the modeled estimate of the long-term mean climate system response to increased radiative forcing with variability averaged out. As with observations, a surface warming is seen in the CMIP5 multimodel mean, extending to $2000 \mathrm{~m}$ around $50^{\circ} \mathrm{S}$. However, as discussed in the introduction, the CMIP5 multimodel mean does not exhibit Southern Ocean surface cooling, or freshening, in contrast to observations. Further, the CMIP5 multimodel mean warming is weaker than observed between 150 and $900 \mathrm{~m}$ at $70^{\circ} \mathrm{S}$. Linear addition of the freshwater simulation trend pattern (Fig. 5b) and the CMIP5 multimodel mean trend pattern (Fig. 5c) yields the pattern shown in Fig. 5d. We add these two trend patterns as while many of the CMIP5 models do show some freshening associated with historical forcings (Figs. 1b and 2), it is generally underestimated compared to observations over the high latitudes. Adding the CMIP5 multimodel mean with underestimated surface freshening (Figs. $4 \mathrm{c}$ and $5 \mathrm{c}$ ) to the freshwater simulations without historical forcings (Figs. $4 \mathrm{~b}$ and $5 \mathrm{~b}$ ) thus provides a useful qualitative comparison to the observations (Figs. 4d and 5d). Qualitatively, this pattern better captures the $55^{\circ}-70^{\circ} \mathrm{S}$ surface cooling and subsurface warming than the CMIP5 multimodel mean alone. This suggests that both Southern Ocean surface freshening and increased radiative forcing are important components in influencing the high-latitude trends in temperature. 

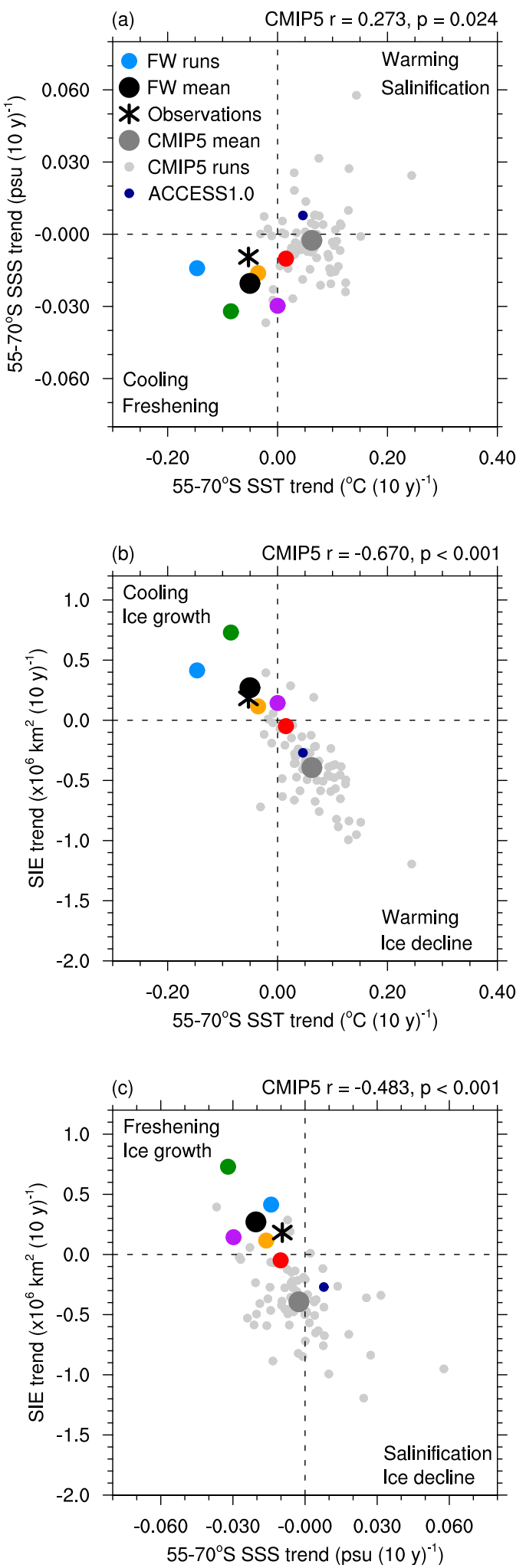

FIG. 8. The 35-yr trends in SSS, SST, and SIE for the ACCESS1.0 freshwater simulations, observations, and CMIP5 models: (a) SSS vs SST, (b) SIE vs SST, and (c) SIE vs SSS. SSS and SST are area-averaged over $55^{\circ}-70^{\circ} \mathrm{S}$. Colored markers show individual freshwater simulations,

\section{c. Intermodel trend comparison}

We next consider the intermodel relationships between the CMIP5 models and the freshwater simulations, to better understand the role freshwater forcing has in influencing Southern Ocean trends. Figure 8 shows areaaveraged trends in Southern Ocean SSS, SST, and SIE for observations (black asterisk), freshwater simulations (colored dots), and CMIP5 models (gray dots). For comparison, the trend from the ACCESS1.0 realization submitted to CMIP5 is also highlighted (small dark blue dot and hereafter referred to as ACCESS1.0 CMIP5). We are particularly interested in the role freshwater forcing plays in influencing the observed sea ice trends, so here we focus on 35-yr trends in all metrics to match the observational sea ice record (as opposed to the 50-yr trends considered previously). Observed SIE and SST trends and CMIP5 SIE, SST, and SSS trends are all calculated over 1979-2013, and all freshwater simulation trends are calculated over the last 35 years of each run to compare periods of equal length. However, because of observational limitations as discussion in section 2c, observed SSS trends are still calculated over 1950-2000.

A moderate intermodel relationships is seen between trends in SSS and SST (Fig. 8a), and strong intermodel relationships are seen between trends in SIE and SST (Fig. 8b), and trends in SIE and SSS (Fig. 8c). In all cases the intermodel relationship between CMIP5 models is statistically significant $(p<0.05)$, although we note that the SST-SSS significance (Fig. 8a) is dependent on inclusion of models at the tail end of the distribution (strong warming and increased salinity), and the observed and ACCESS1.0 freshwater simulation trends fit the relationship shown by the CMIP5 models. Models or runs that show a stronger surface freshening also tend to show a stronger surface cooling and an increase in sea ice (or at least a weaker decrease in sea ice). Models or runs that show a stronger surface salinification tend to warm more and show a larger decline in sea ice.

the freshwater ensemble mean is shown by a black dot, observations are shown by a black asterisk, the CMIP5 multimodel mean is shown by a dark gray dot, the CMIP5 models are shown by light gray markers, and the ACCESS1.0 CMIP5 run is shown by a small dark blue marker. Observed SST and SIE trends and CMIP5 trends are calculated over 1979-2013. Freshwater simulation trends are calculated for the last 35 years of the experiments, to cover a comparable length period to the CMIP5 models and SIE and SST observations. Because of observational limitations as discussed in section 2c, observed SSS trends are calculated over 1950-2000 (i.e., the observed SSS trends cover a different period of different length than all other points shown). 
The majority of CMIP5 models do not simulate a surface cooling and increase in sea ice (Fig. 8b), as seen in observations, which has previously been linked in part to a summertime mechanism related to underestimation of the westerly wind intensification, leading to an underestimation of increased Ekman upwelling, which in summer is associated with surface cooling (Purich et al. 2016a). This intermodel relationship occurs because during summer the surface water that receives shortwave radiation resides in a thin layer at the surface $(0-20 \mathrm{~m})$, forming a cap over cool winter water (20-150 m). Thus, enhanced Ekman upwelling during summer brings cooler winter water to the surface, and this surface cooling spreads north as a result of equatorward Ekman transport. Wind-driven Ekman upwelling seems to dominate over salinity-driven stratification during summer, and thus the intermodel trend relationship between SSS and SST is not statistically significant (Fig. S7 in the supplemental material).

During winter there is no warm layer at the surface, and the ocean is stratified between cold freshwater at the surface and warm salty water at depth. Given these water column characteristics, salinity-driven stratification becomes more strongly linked to surface temperature, and the intermodel trend relationship between SSS and SST is strengthened during the winter season (Fig. S8 in the supplemental material; $p<0.01$, although again the significance of this relationship is dependent on including models at the tail ends of the distribution). When considering the annual-mean temperature profile, on average warmer waters reside below cooler surface waters; as such, increased stability and reduced upwelling cause surface cooling, as seen in the relationship between SSS and SST trends in Fig. 8a. Whereas the vast majority of CMIP5 models do not lie in the same quadrant as the observed trends (with SSS trends over 1950-2000), the majority of the freshwater simulations and the freshwater ensemble mean trends do, demonstrating a similarity between the freshwater simulations and observations not shared by the majority of CMIP5 models. However, we note that while the observed SSS trend over 1950-2000 provides a general indication of the long-term trend, because of observational limitations we cannot actually know what quadrant the observed trends with SSS calculated over 1979-2013 lie in (Figs. 8a,c). We also note that our freshwater simulations do not include anthropogenic forcings, so while they do indeed simulate a freshening and cooling, this may not be the case with the same freshening imposed under global warming conditions.

It is also worth noting the spread across the five freshwater simulations (Fig. 8), which have identical forcings and differ only in their initial conditions. While the freshwater simulations fit the CMIP5 intermodel trend relationship in each case (Figs. 8a-c), the spread among the five ensemble members highlights that the Southern Ocean hydrography exhibits notable multidecadal variability, presumably driven by multidecadal secular variability in atmospheric forcing (e.g., via decadal variability in the SAM). This also emphasizes the limitations of assessing Southern Ocean trends over 35 years, a period that may not accurately represent longerterm trends because of aliased multidecadal variability (Goosse et al. 2009; Jones et al. 2016; Hobbs et al. 2016). When 50-yr trends are considered for all metrics for both the freshwater simulations and the CMIP5 realizations (Fig. S9 in the supplemental material), the variability across ensemble member trends greatly reduces, diminishing the spread across both the freshwater and CMIP5 simulations.

\section{d. Salinity restoring simulations}

While this study focuses on the output from the ACCESS1.0 idealized freshwater simulations, regional differences between observations and modeled trends in SSS can be seen (Figs. 3a,b). In particular, the model redistribution of the applied idealized freshwater flux results in little surface freshening of the Ross Sea, but considerable pooling of freshwater in the Bellingshausen Sea (Fig. 3b), resulting in SSS trends that exhibit an opposite dipole pattern to what is observed in these regions (Fig. 3a). To complement the idealized freshwater simulations and apply more realistic geographic distributions of trends, we also conduct a pair of SSS restoring simulations: one is an unperturbed control run and the second is identical to the control, but with an applied freshening of surface salinity that spatially matches the Durack and Wijffels (2010) trends. In the first simulation, SSS between $40^{\circ}$ and $70^{\circ} \mathrm{S}$ (with tapering either side) is restored to the annually and monthly varying SSS of the piControl over a 50-yr reanalyzed segment of the run. In the second simulation, an annually increasing trend is superimposed onto the piControl SSS in the $40^{\circ}-70^{\circ} \mathrm{S}$ restoring region. This applied SSS trend is set to exactly match the observed Durack and Wijffels (2010) trends. Because of the different experimental setup, compared to the idealized freshwater simulations, these SSS restoring simulations enable better resolution of the geographic distribution of observed SSS trends. Both restoring simulations are branched from the same year of the piControl and run for 50 years each. The SSS restoring time scale is 15 days over the upper-ocean model layer.

We difference the two SSS restoring simulations to obtain the signal due to the Durack and Wijffels (2010) SSS trend, shown in Fig. 9. The SSS restoring difference pattern (Fig. 9b) accurately captures the observed SSS 
(a) D\&W 2010 SSS trends (PSU $\left.(10 \mathrm{y})^{-1}\right)$
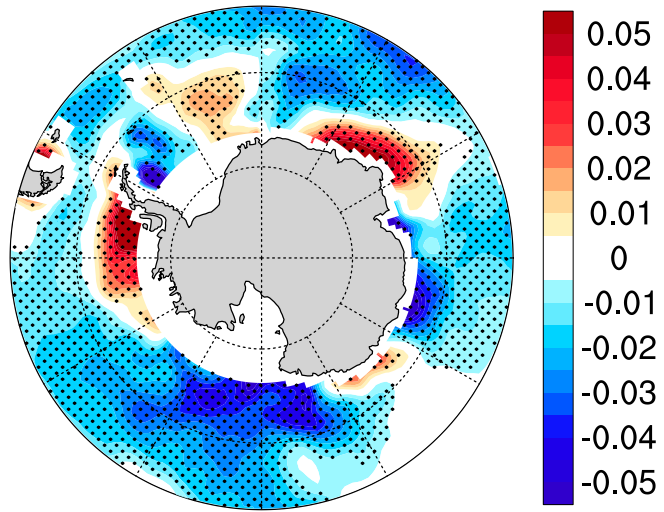

(c) HadISST SST trends $\left({ }^{\circ} \mathrm{C}(10 \mathrm{y})^{-1}\right)$
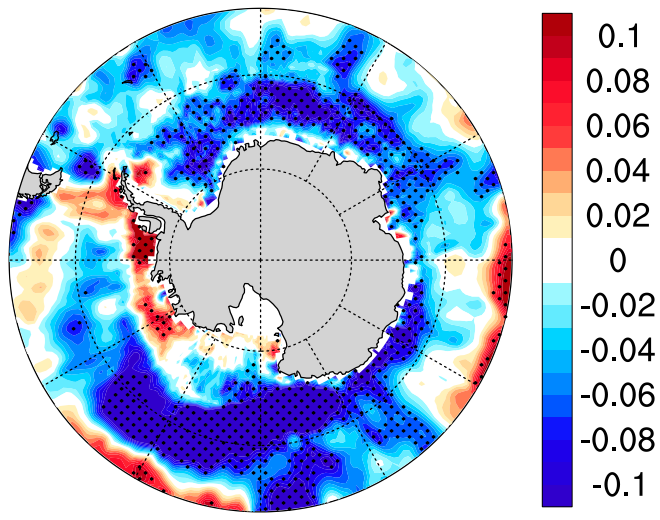

(e) NSIDC Bootstrap SIC trends $\left(\%(10 y)^{-1}\right)$
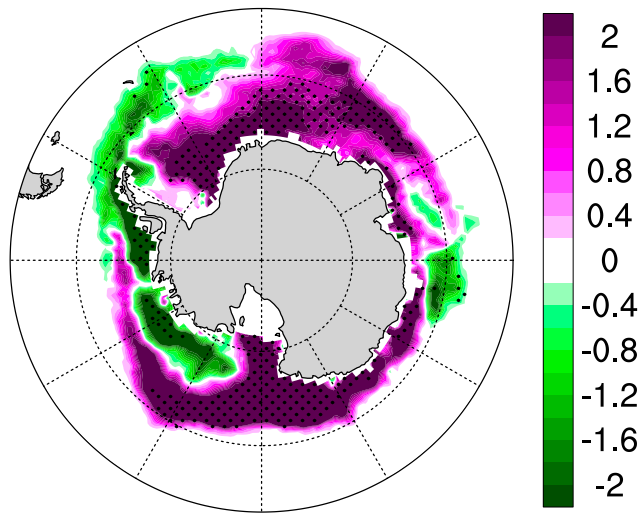

(b) ACCESS1.0 SSS trends (PSU $\left.(10 \mathrm{y})^{-1}\right)$

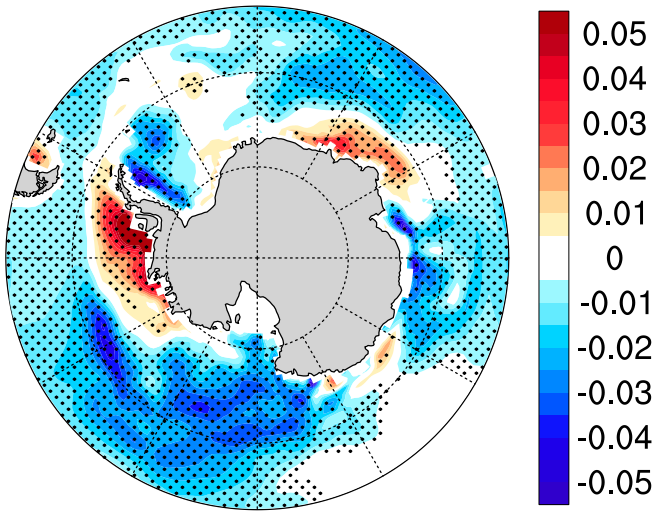

(d) ACCESS1.0 SST trends $\left({ }^{\circ} \mathrm{C}(10 \mathrm{y})^{-1}\right)$

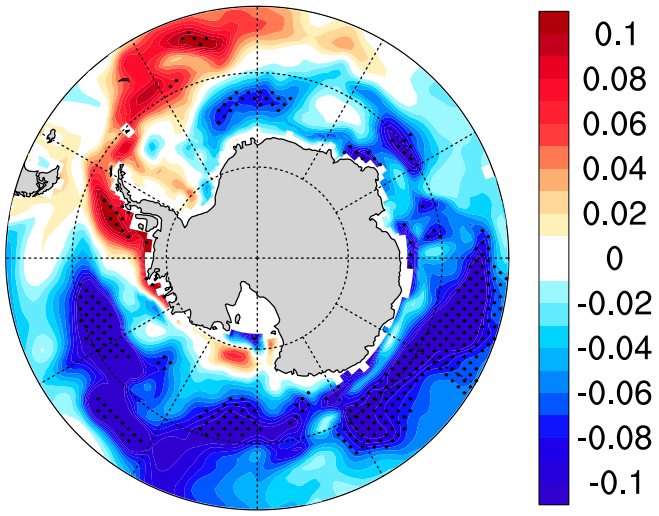

(f) ACCESS1.0 SIC trends $\left(\%(10 \mathrm{y})^{-1}\right)$

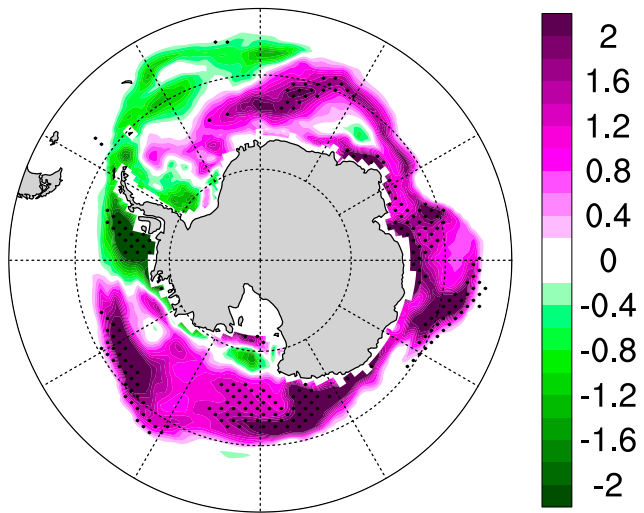

FIG. 9. (left) Observed and (right) 50-yr trends from differencing the ACCESS1.0 SSS restoring simulations: (a),(b) SSS trends, (c),(d) SST trends, and (e),(f) SIC trends. Note that (a),(c),(e) are identical to Figs. 3a,c,e and are included here for direct comparison. In all panels, stippling indicates trend significance at the $95 \%$ level. Observations are as in Fig. 3.

trend pattern (Fig. 9a), as expected given the restoring technique, with only minor differences evident. The SST (Fig. 9d) and SIC (Fig. 9f) trend patterns that result from this SSS restoring approach also resemble the observed
(Figs. 9c,e) trends remarkably well. The observed SSS changes drive cooling around most regions of Antarctica, and an accompanying increase in sea ice in the restoring simulations, as well as the characteristic 
warming and decrease in SIC in the Bellingshausen Sea and along the Antarctic Peninsula. There are also some differences between the observed and simulated trends. In particular, in contrast to the observed cooling, a strong warming is simulated in the South Atlantic (Figs. 9c,d). Overall however, the SST trend patterns south of $60^{\circ} \mathrm{S}$ show remarkable agreement. Minor regional differences in the SIC trend patterns (Figs. 9e,f) appear in the inner Amundsen Sea and at $90^{\circ} \mathrm{E}$, but overall the SIC trend patterns show strong similarities. These SSS restoring simulations demonstrate that without any mechanical forcing associated with changing winds, SSS can drive changes in SST, and remarkably that the regional pattern of SSS trends can drive the dipole trends in SST and sea ice in the Pacific sector. This reinforces the findings presented above, based on the freshwater simulations that demonstrate how reduced upwelling of warmer subsurface waters induced by large-scale freshening trends has played an important role in the recent multidecadal cooling of the surface Southern Ocean.

\section{Discussion}

The Southern Ocean surface has freshened in recent decades (Durack and Wijffels 2010; de Lavergne et al. 2014), increasing water column stability and reducing the upwelling of warm subsurface waters. While previous studies have investigated the influence of increased freshwater from Antarctic ice sheet and shelf runoff and iceberg fluxes around the continental margins (Bintanja et al. 2013, 2015; Swart and Fyfe 2013; Pauling et al. 2016), the impact of broad-scale freshening resulting from a combination of factors, including freshwater redistribution by sea ice and icebergs, increased ice sheet and ice shelf runoff, and $P-E$ changes likely associated with the positive SAM trend, has received little attention. The possible role that this broadscale freshening has had on Antarctic sea ice trends and surface Southern Ocean cooling provided the overall motivation for this study. To this end, we examined targeted coupled climate model simulations run using ACCESS1.0 with increased freshwater applied to the ocean model component over the Southern Ocean.

In terms of the total mass of freshwater applied in our simulations, the freshwater trend of $0.1 \mathrm{~mm} d a y^{-1}$ $(10 \mathrm{yr})^{-1}$ applied in our simulations over $55^{\circ}-70^{\circ} \mathrm{S}$ corresponds to a freshwater mass acceleration of approximately $112 \mathrm{Gt} \mathrm{yr}^{-2}\left(\sim 5600 \mathrm{Gt} \mathrm{yr}^{-1}\right.$ in the last year of the simulations), chosen to simulate a clear surface freshening as observed. To put this into context, Pauling et al. (2016) found the increase in $P-E$ over the Southern Ocean (south of $50^{\circ} \mathrm{S}$, not including Antarctica) from the preindustrial period to the present day to be approximately
$2000 \mathrm{Gt} \mathrm{yr}^{-1}$ in the CMIP5 models, although with considerable spread across models (see their Fig. 5c). The additional freshwater applied in our idealized simulations is considerably higher than this, as the majority of CMIP5 models underestimate the surface freshening trends over the Southern Ocean (Fig. 1b). Our idealized freshwater simulations show that a surface freshening causes a decrease in SST and an increase in sea ice, attributed primarily to a reduction in ocean convection. However, to achieve a cooling and SIE increase similar to observations, a stronger than observed zonal-mean freshening was applied (Fig. 8). This suggests that a uniform broad-scale surface freshening from processes including increased $P-E$ is only one component contributing to observed sea ice changes and surface cooling; other factors such as decadal variability (Meehl et al. 2016; Purich et al. 2016b), direct wind effects (Holland and Kwok 2012; Purich et al. 2016a), and zonal variations in SSS (as per our SSS restoring simulations; Fig. 9) also play a critical role.

Comparisons with results from Bintanja et al. (2013), Bintanja et al. (2015), and Pauling et al. (2016) are difficult, as their experiments added constant, rather than increasing, amounts of freshwater, and in addition their focus is on the impacts of Antarctic meltwater discharge, not the broad-scale freshening due to precipitation trends examined here. While Bintanja et al. (2013) added a relatively modest $250 \mathrm{Gt} \mathrm{yr}^{-1}$ over 31 years with radiative forcing held fixed, when differenced from their control experiment, sea ice was found to increase. In similar simulations with increased radiative forcing, Bintanja et al. (2015) added only $10-120 \mathrm{Gt} \mathrm{yr}^{-1}$ of freshwater and found that $120 \mathrm{Gt} \mathrm{yr}^{-1}$ was enough to offset radiative forcing and result in a weak increase in sea ice. On the other hand, the surface freshwater experiments by Pauling et al. (2016) added 1000-3000 $\mathrm{Gt} \mathrm{yr}^{-1}$, and while they found an increase in mean-state sea ice area, they did not find a positive trend in sea ice under increased radiative forcing conditions. While these studies are very useful in better understanding how a constant additional freshwater flux governs changes in sea ice, motivated by the lack of constant Antarctic ice shelf and sheet runoff and iceberg fluxes in the CMIP5 models, without timevarying freshwater fluxes, it is difficult to compare these studies to the real-world surface freshening trend that has been observed (Durack and Wijffels 2010).

The study by Swart and Fyfe (2013) is more comparable to this study, as they also applied increasing amounts of freshwater, although their freshwater flux was only applied around the Antarctic margin, compared to the broad-scale additional flux in our simulations. Their additions ranged from 3.15 to $15.77 \mathrm{Gt} \mathrm{yr}^{-2}$ over 47 years $\left(\sim 740 \mathrm{Gt} \mathrm{yr}^{-1}\right.$ in the last year of the simulation for the highest acceleration rate) and 
from 3.15 to $31.54 \mathrm{Gt} \mathrm{yr}^{-2}$ over 29 years $\left(\sim 910 \mathrm{Gt} \mathrm{yr}^{-1}\right.$ in the last year of the simulation for the highest acceleration rate). These freshwater additions are considerably less than those applied in our experiments, as we are interested in broad-scale freshening from processes including $P-E$ changes, whereas Swart and Fyfe (2013) were interested in the Antarctic ice sheet meltwater. The simulations by Swart and Fyfe (2013) also included increased radiative forcing, and they found that the additional freshwater in their simulations reduced the amount of sea ice lost, but could not reverse the negative sea ice trend. Despite this, relative to their control experiment, their strongest freshwater mass accelerations gave regional SIC trends on the order of $0.5-2.5 \%(10 \mathrm{yr})^{-1}$ [Fig. 4d in Swart and Fyfe (2013)], which are comparable to our SIC trends (Fig. 3f).

We show that the majority of CMIP5 models underestimate the observed surface freshening over the Southern Ocean over the latter half of the twentieth century. Based on the intermodel CMIP5 trend relationships assessed here, alongside our freshwater anomaly experiments conducted using ACCESS1.0, this reduced or absent freshening highly likely contributes to the poor simulation of observed Southern Ocean surface cooling and Antarctic sea ice trends in CMIP5 models. However, compared to the CMIP5 models and the real world, we note that our freshwater simulations are idealized and do not include anthropogenic greenhouse warming. The historical and RCP8.5 ACCESS1.0 simulation participating in CMIP5 shows a Southern Ocean SST warming of approximately $0.05^{\circ} \mathrm{C}(10 \mathrm{yr})^{-1}$ over $1979-2013$, between $55^{\circ}$ and $70^{\circ} \mathrm{S}$, as well as a weak increase in surface salinity over this latitude band. In contrast, the ensemble mean of our idealized freshwater simulations shows a cooling over this same latitude band of approximately $-0.05^{\circ} \mathrm{C}(10 \mathrm{yr})^{-1}$. Similarly, the historical and RCP8.5 ACCESS1.0 simulation exhibits a significant sea ice retreat over this period $\left[\sim-0.2710^{6} \mathrm{~km}^{2}(10 \mathrm{yr})^{-1}\right]$, while adding a surface freshening trend in our idealized freshwater simulations leads to the opposite sea ice tendencies; namely, an ensemble-mean expansion in Antarctic sea ice that happens to be of similar magnitude $\left[\sim 0.2710^{6} \mathrm{~km}^{2}(10 \mathrm{yr})^{-1}\right]$. The freshening-induced cooling we obtain could thus clearly be one of the important factors accounting for the regional model-observation mismatch in recent SST and SIC trends, alongside decadal variability and direct wind effects. Furthermore, the strong relationships obtained between Southern Ocean surface salinity and temperature trends demonstrate the importance of surface freshening in this region for upper-ocean thermal properties. Had the historical greenhouse warming been added alongside the surface freshening in our idealized freshwater simulations, the influence of these two factors might have more or less canceled to yield a minimal trend in Southern Ocean SST and SIE; this will be the focus of future work (see also Fig. S10 in the supplemental material).

Many of the features of both SST and sea ice trends in the region, including warming and reduced sea ice in the Amundsen and Bellingshausen Seas and cooling and increased sea ice in the Ross Sea, can be accurately simulated when simply imposing the observed SSS trends over the Southern Ocean in SSS restoring simulations. This demonstrates that upper-ocean SSS trends have been an important component in driving regional hydrography and circulation changes around Antarctica over the last half century. This study also highlights the importance of accurately simulating changes in clouds, storm tracks, $P-E$, and surface salinity over the Southern Ocean to capture changes in ocean circulation and sea ice.

Acknowledgments. This work was supported by the Australian Research Council (ARC) including the ARC Centre of Excellence for Climate System Science (CE110001028), and CSIRO Oceans and Atmosphere. A.P. was supported by an Australian Postgraduate Award, a UNSW Research Excellence scholarship, and a CSIRO Office of the Chief Executive Science Leader scholarship. M.H.E. was supported by an ARC Laureate Fellowship (FL100100214). W.C. was supported by the Centre for Southern Hemisphere Oceans Research, a joint research centre between QNLM and CSIRO. The work of P.J.D. from Lawrence Livermore National Laboratory was performed under the auspices of the U.S. Department of Energy, Office of Science, Climate and Environmental Sciences Division, Regional and Global Model Analysis Program under Contract DEAC52-07NA27344. This research was undertaken with the assistance of resources and services from the National Computational Infrastructure (NCI), which is supported by the Australian Government. Figures were produced using the NCAR Command Language (https://doi.org/10.5065/ D6WD3XH5). We acknowledge the World Climate Research Programme's Working Group on Coupled Modelling, which is responsible for CMIP, and thank the climate modelling groups for producing and making available their model output. We also thank the three anonymous reviewers for their helpful comments.

\section{REFERENCES}

Adler, R. F., and Coauthors, 2003: The version-2 Global Precipitation Climatology Project (GPCP) monthly precipitation analysis (1979-present). J. Hydrometeor., 4, 1147-1167, https://oi.org/ 10.1175/1525-7541(2003)004<1147:TVGPCP $>2.0 . C O ; 2$.

Aiken, C. M., and M. H. England, 2008: Sensitivity of the presentday climate to freshwater forcing associated with Antarctic sea 
ice loss. J. Climate, 21, 3936-3946, https://doi.org/10.1175/ 2007JCLI1901.1.

Armour, K. C., J. Marshall, J. R. Scott, A. Donohoe, and E. R. Newsom, 2016: Southern Ocean warming delayed by circumpolar upwelling and equatorward transport. Nat. Geosci., 9, 549-554, https:// doi.org/10.1038/ngeo2731.

Beckmann, A., and H. Goosse, 2003: A parameterization of ice shelf-ocean interaction for climate models. Ocean Modell., 5, 157-170, https://doi.org/10.1016/S1463-5003(02)00019-7.

Bi, D., and Coauthors, 2013a: ACCESS-OM: The ocean and seaice core of the ACCESS coupled model. Aust. Meteor. Oceanogr. J., 63, 213-232, https://doi.org/10.22499/2.6301.014.

_- and Coauthors, 2013b: The ACCESS coupled model: Description, control climate and evaluation. Aust. Meteor. Oceanogr. J., 63, 41-64, https://doi.org/10.22499/2.6301.004.

Bintanja, R., G. van Oldenborgh, S. Drijfhout, B. Wouters, and C. Katsman, 2013: Important role for ocean warming and increased ice-shelf melt in Antarctic sea-ice expansion. Nat. Geosci., 6, 376-379, https://doi.org/10.1038/ngeo1767.

,$- \ldots$, and C. Katsman, 2015: The effect of increased fresh water from Antarctic ice shelves on future trends in Antarctic sea ice. Ann. Glaciol., 56, 120-126, https://doi.org/10.3189/ 2015AoG69A001.

Boyer, T. P., S. Levitus, J. Antonov, R. Locarnini, and H. Garcia, 2005: Linear trends in salinity for the World Ocean, 19551998. Geophys. Res. Lett., 32, L01604, https://doi.org/10.1029/ 2004GL021791.

Bracegirdle, T. J., E. F. Shuckburgh, J.-B. Sallee, Z. Wang, A. J. Meijers, N. Bruneau, T. Phillips, and L. J. Wilcox, 2013: Assessment of surface winds over the Atlantic, Indian, and Pacific ocean sectors of the Southern Ocean in CMIP5 models: Historical bias, forcing response, and state dependence. J. Geophys. Res. Atmos., 118, 547-562, https://doi.org/10.1002/jgrd.50153.

Bromwich, D. H., J. P. Nicolas, and A. J. Monaghan, 2011: An assessment of precipitation changes over Antarctica and the Southern Ocean since 1989 in contemporary global reanalyses. J. Climate, 24, 4189-4209, https://doi.org/10.1175/ 2011JCLI4074.1.

Cavalieri, D., and C. L. Parkinson, 2008: Antarctic sea ice variability and trends, 1979-2006. J. Geophys. Res., 113, C07004, https:// doi.org/10.1029/2007JC004564.

Comiso, J. C., and F. Nishio, 2008: Trends in the sea ice cover using enhanced and compatible AMSR-E, SSM/I, and SMMR data. J. Geophys. Res., 113, C02S07, https://doi.org/10.1029/ 2007JC004257.

Davies, T., M. J. P. Cullen, A. J. Malcolm, M. H. Mawson, A. Staniforth, A. A. White, and N. Wood, 2005: A new dynamical core for the Met Office's global and regional modelling of the atmosphere. Quart. J. Roy. Meteor. Soc., 131, 1759-1782, https://doi.org/10.1256/qj.04.101.

Dee, D., and Coauthors, 2011: The ERA-Interim reanalysis: Configuration and performance of the data assimilation system. Quart. J. Roy. Meteor. Soc., 137, 553-597, https://doi.org/ 10.1002/qj.828.

de Lavergne, C., J. B. Palter, E. D. Galbraith, R. Bernardello, and I. Marinov, 2014: Cessation of deep convection in the open Southern Ocean under anthropogenic climate change. Nat. Climate Change, 4, 278-282, https://doi.org/10.1038/ nclimate2132.

Dix, M., and Coauthors, 2013: The ACCESS coupled model: Documentation of core CMIP5 simulations and initial results. Aust. Meteor. Oceanogr. J., 63, 83-99, https://doi.org/10.22499/ 2.6301.006.
Durack, P. J., 2015: Ocean salinity and the global water cycle. Oceanography, 28, 20-31, https://doi.org/10.5670/ oceanog.2015.03.

— linities and their relationship to broad-scale warming. J. Climate, 23, 4342-4362, https://doi.org/10.1175/2010JCLI3377.1.

,-- , and R. J. Matear, 2012: Ocean salinities reveal strong global water cycle intensification during 1950 to 2000. Science, 336, 455-458, https://doi.org/10.1126/science.1212222.

_ P. J. Gleckler, F. W. Landerer, and K. E. Taylor, 2014: Quantifying underestimates of long-term upper-ocean warming. Nat. Climate Change, 4, 999-1005, https://doi.org/10.1038/ nclimate2389.

England, M. H., 1993: Representing the global-scale water masses in ocean general circulation models. J. Phys. Oceanogr., 23, 1523-1552, https://doi.org/10.1175/1520-0485(1993)023<1523: RTGSWM $>2.0 . \mathrm{CO} ; 2$.

Fan, T., C. Deser, and D. P. Schneider, 2014: Recent Antarctic sea ice trends in the context of Southern Ocean surface climate variations since 1950. Geophys. Res. Lett., 41, 2419-2426, https://doi.org/10.1002/2014GL059239.

Fetterer, F., K. Knowles, W. Meier, and M. Savoie, 2002: Sea Ice Index (subset: Antarctic). National Snow and Ice Data Center, accessed February 2015, https:/doi.org/10.7265/N5K072F8.

Frederiksen, J. S., and C. S. Frederiksen, 2007: Interdecadal changes in Southern Hemisphere winter storm track modes. Tellus, 59A, 599-617, https://doi.org/10.1111/ j.1600-0870.2007.00264.x.

Fyfe, J. C., 2003: Extratropical Southern Hemisphere cyclones: Harbingers of climate change? J. Climate, 16, 2802-2805, https:// doi.org/10.1175/1520-0442(2003)016<2802:ESHCHO>2.0.CO;2.

Gagné, M.-E., N. P. Gillett, and J. C. Fyfe, 2015: Observed and simulated changes in Antarctic sea ice extent over the past 50 years. Geophys. Res. Lett., 42, 90-95, https://doi.org/10.1002/ 2014 GL062231.

Good, S. A., M. J. Martin, and N. A. Rayner, 2013: EN4: Quality controlled ocean temperature and salinity profiles and monthly objective analyses with uncertainty estimates. J. Geophys. Res. Oceans, 118, 6704-6716, https://doi.org/ 10.1002/2013JC009067.

Goosse, H., and V. Zunz, 2014: Decadal trends in the Antarctic sea ice extent ultimately controlled by ice-ocean feedback. Cryosphere, 8, 453-470, https://doi.org/10.5194/tc-8-453-2014.

—, W. Lefebvre, A. de Montety, E. Crespin, and A. Orsi, 2009: Consistent past half-century trends in the atmosphere, the sea ice and the ocean at high southern latitudes. Climate Dyn., 33, 999-1016, https://doi.org/10.1007/s00382-008-0500-9.

Gregory, J. M., 2000: Vertical heat transports in the ocean and their effect on time-dependent climate change. Climate Dyn., 16, 501-515, https://doi.org/10.1007/s003820000059.

Griffies, S., M. Schmidt, and M. Herzfeld, 2010: Elements of MOM4p1. GFDL Ocean Group Tech. Rep. 6, 444 pp.

Haumann, F. A., N. Gruber, M. Münnich, I. Frenger, and S. Kern, 2016: Sea-ice transport driving Southern Ocean salinity and its recent trends. Nature, 537, 89-92, https://doi.org/10.1038/nature19101.

Hellmer, H. H., 2004: Impact of Antarctic ice shelf basal melting on sea ice and deep ocean properties. Geophys. Res. Lett., 31, L10307, https://doi.org/10.1029/2004GL019506.

Helm, K. P., N. L. Bindoff, and J. A. Church, 2010: Changes in the global hydrological cycle inferred from ocean salinity. Geophys. Res. Lett., 37, L18701, https://doi.org/10.1029/2010GL044222.

Hobbs, W. R., R. Massom, S. Stammerjohn, P. Reid, G. Williams, and W. Meier, 2016: A review of recent changes in Southern 
Ocean sea ice, their drivers and forcings. Global Planet. Change, 143, 228-250, https://doi.org/10.1016/j.gloplacha.2016.06.008.

Holland, P. R., and R. Kwok, 2012: Wind-driven trends in Antarctic sea-ice drift. Nat. Geosci., 5, 872-875, https://doi.org/ 10.1038/ngeo1627.

Hosoda, S., T. Suga, N. Shikama, and K. Mizuno, 2009: Global surface layer salinity change detected by Argo and its implication for hydrological cycle intensification. J. Oceanogr., 65 579, https://doi.org/10.1007/s10872-009-0049-1.

Hunke, E. C., and W. H. Lipscomb, 2010: CICE: The Los Alamos Sea Ice Model documentation and software user's manua version 4.1. Los Alamos National Laboratory Tech Rep. LA-CC-06-012, $76 \mathrm{pp}$.

Ivanova, D. P., P. J. Gleckler, K. E. Taylor, P. J. Durack, and K. D. Marvel, 2016: Moving beyond the total sea ice extent in gauging model biases. J. Climate, 29, 8965-8987, https:// doi.org/10.1175/JCLI-D-16-0026.1.

Jones, J. M., and Coauthors, 2016: Assessing recent trends in high-latitude Southern Hemisphere surface climate. Nat. Climate Change, 6, 917-926, https://doi.org/10.1038/ nclimate3103.

Josey, S. A., S. Gulev, and L. Yu, 2013: Exchanges through the ocean surface. Ocean Circulation and Climate: A 21 Century Perspective, G. Siedler et al., Eds., Vol. 103, International Geophysics Series, Elsevier, 115-140, https://doi.org/10.1016/ B978-0-12-391851-2.00005-2.

Kirkman, C. H., and C. M. Bitz, 2011: The effect of the sea ice freshwater flux on Southern Ocean temperatures in CCSM3: Deep-ocean warming and delayed surface warming. J. Climate, 24, 2224-2237, https://doi.org/10.1175/2010JCLI3625.1.

Lago, V., S. E. Wijffels, P. J. Durack, J. A. Church, N. L. Bindoff, and S. J. Marsland, 2016: Simulating the role of surface forcing on observed multidecadal upper-ocean salinity changes. J. Climate, 29, 5575-5588, https://doi.org/10.1175/ JCLI-D-15-0519.1.

Large, W. G., and S. G. Yeager, 2009: The global climatology of an interannually varying air-sea flux data set. Climate Dyn., 33, 341-364, https://doi.org/10.1007/s00382-008-0441-3.

Li, X., D. M. Holland, E. P. Gerber, and C. Yoo, 2014: Impacts of the north and tropical Atlantic Ocean on the Antarctic Peninsula and sea ice. Nature, 505, 538-542, https://doi.org/ 10.1038 /nature12945.

Liu, J., and J. A. Curry, 2010: Accelerated warming of the Southern Ocean and its impacts on the hydrological cycle and sea ice. Proc. Natl. Acad. Sci. USA, 107, 14 987-14 992, https://doi.org/ 10.1073/pnas.1003336107.

Mahlstein, I., P. R. Gent, and S. Solomon, 2013: Historical Antarctic mean sea ice area, sea ice trends, and winds in CMIP5 simulations. J. Geophys. Res. Atmos., 118, 5105-5110, https:// doi.org/10.1002/jgrd.50443.

Marshall, G. J., 2003: Trends in the southern annular mode from observations and reanalyses. J. Climate, 16, 4134-4143, https:// doi.org/10.1175/1520-0442(2003)016<4134:TITSAM >2.0.CO;2.

Marshall, J., K. C. Armour, J. R. Scott, Y. Kostov, U. Hausmann, D. Ferreira, T. G. Shepherd, and C. M. Bitz, 2014: The ocean's role in polar climate change: Asymmetric Arctic and Antarctic responses to greenhouse gas and ozone forcing. Philos. Trans. Roy. Soc., 372A, 20130040, https://doi.org/ 10.1098/rsta.2013.0040.

Marsland, S. J., and J.-O. Wolff, 2001: On the sensitivity of Southern Ocean sea ice to the surface freshwater flux: A model study. J. Geophys. Res., 106, 2723-2741, https://doi.org/ 10.1029/2000JC900086.
Martin, G. M., and Coauthors, 2011: The HadGEM2 family of Met Office Unified Model climate configurations. Geosci. Model Dev., 4, 723-757, https://doi.org/10.5194/gmd-4-723-2011.

- S. F. Milton, C. A. Senior, M. E. Brooks, S. Ineson, T. Reichler, and J. Kim, 2010: Analysis and reduction of systematic errors through a seamless approach to modeling weather and climate. J. Climate, 23, 5933-5957, https://doi.org/ 10.1175/2010JCLI3541.1.

Martinson, D. G., 1990: Evolution of the Southern Ocean winter mixed layer and sea ice: Open ocean deepwater formation and ventilation. J. Geophys. Res. Oceans, 95, 11 641-11 654, https:// doi.org/10.1029/JC095iC07p11641.

Meehl, G. A., J. M. Arblaster, C. M. Bitz, C. T. Chung, and H. Teng, 2016: Antarctic sea-ice expansion between 2000 and 2014 driven by tropical Pacific decadal climate variability. Nat. Geosci., 9, 590-595, https://doi.org/10.1038/ngeo2751.

Meier, W., F. Fetterer, M. Savoie, S. Mallory, R. Duerr, and J. Stroeve, 2015: NOAA/NSIDC climate data record of passive microwave sea ice concentration, version 2 (subset: Southern Hemisphere). NSIDC, accessed August 2014, http:// nsidc.org/data/G02202/versions/2.

Morrison, A. K., M. H. England, and A. M. Hogg, 2015: Response of Southern Ocean convection and abyssal overturning to surface buoyancy perturbations. J. Climate, 28, 4263-4278, https://doi.org/10.1175/JCLI-D-14-00110.1.

Parkinson, C. L., and D. Cavalieri, 2012: Antarctic sea ice variability and trends, 1979-2010. Cryosphere, 6, 871-880, https:// doi.org/10.5194/tc-6-871-2012.

Pauling, A. G., C. M. Bitz, I. J. Smith, and P. J. Langhorne, 2016: The response of the Southern Ocean and Antarctic sea ice to fresh water from ice shelves in an Earth system model. J. Climate, 29, 1655-1672, https://doi.org/10.1175/JCLI-D-15-0501.1.

Polvani, L. M., and K. L. Smith, 2013: Can natural variability explain observed Antarctic sea ice trends? New modeling evidence from CMIP5. Geophys. Res. Lett., 40, 3195-3199, https://doi.org/10.1002/grl.50578.

Purich, A., and S.-W. Son, 2012: Impact of Antarctic ozone depletion and recovery on Southern Hemisphere precipitation, evaporation, and extreme changes. J. Climate, 25, 3145-3154, https://doi.org/10.1175/JCLI-D-11-00383.1.

, T. Cowan, S.-K. Min, and W. Cai, 2013: Autumn precipitation trends over Southern Hemisphere midlatitudes as simulated by CMIP5 models. J. Climate, 26, 8341-8356, https://doi.org/ 10.1175/JCLI-D-13-00007.1.

, W. Cai, M. H. England, and T. Cowan, 2016a: Evidence for link between modelled trends in Antarctic sea ice and underestimated westerly wind changes. Nat. Commun., 7, 10409, https://doi.org/10.1038/ncomms10409.

- , and Coauthors, 2016b: Tropical Pacific SST drivers of recent Antarctic sea ice trends. J. Climate, 29, 8931-8948, https:// doi.org/10.1175/JCLI-D-16-0440.1.

Rayner, N., D. E. Parker, E. Horton, C. K. Folland, L. Alexander, D. Rowell, E. Kent, and A. Kaplan, 2003: Global analyses of sea surface temperature, sea ice, and night marine air temperature since the late nineteenth century. J. Geophys. Res., 108, 4407, https://doi.org/10.1029/2002JD002670.

Sen Gupta, A., and M. H. England, 2006: Coupled oceanatmosphere-ice response to variations in the southern annular mode. J. Climate, 19, 4457-4486, https://doi.org/10.1175/ JCLI3843.1.

, N. C. Jourdain, J. N. Brown, and D. P. Monselesan, 2013: Climate drift in the CMIP5 models. J. Climate, 26, 8597-8615, https:// doi.org/10.1175/JCLI-D-12-00521.1. 
Simpkins, G. R., L. M. Ciasto, D. W. Thompson, and M. H. England, 2012: Seasonal relationships between large-scale climate variability and Antarctic sea ice concentration. J. Climate, 25, 5451-5469, https://doi.org/10.1175/JCLI-D-11-00367.1.

- S. McGregor, A. S. Taschetto, L. M. Ciasto, and M. H. England, 2014: Tropical connections to climatic change in the extratropical Southern Hemisphere: The role of Atlantic SST trends. J. Climate, 27, 4923-4936, https://doi.org/10.1175/JCLI-D-13-00615.1.

Skliris, N., R. Marsh, S. A. Josey, S. A. Good, C. Liu, and R. P. Allan, 2014: Salinity changes in the World Ocean since 1950 in relation to changing surface freshwater fluxes. Climate Dyn., 43, 709736, https://doi.org/10.1007/s00382-014-2131-7.

Son, S.-W., N. F. Tandon, L. M. Polvani, and D. W. Waugh, 2009: Ozone hole and Southern Hemisphere climate change. Geophys. Res. Lett., 36, L15705, https://doi.org/10.1029/ 2009GL038671.

Swart, N. C., and J. C. Fyfe, 2012: Observed and simulated changes in the Southern Hemisphere surface westerly wind-stress. Geophys. Res. Lett., 39, L16711, https://oi.org/10.1029/2012GL052810.

, and _ 2013: The influence of recent Antarctic ice sheet retreat on simulated sea ice area trends. Geophys. Res. Lett., 40, 4328-4332, https://doi.org/10.1002/grl.50820.

Thompson, D. W., and S. Solomon, 2002: Interpretation of recent Southern Hemisphere climate change. Science, 296, 895-899, https://doi.org/10.1126/science.1069270.

Trenberth, K. E., Y. Zhang, and M. Gehne, 2017: Intermittency in precipitation: Duration, frequency, intensity, and amounts using hourly data. J. Hydrometeor., 18, 1393-1412, https://doi.org/ 10.1175/JHM-D-16-0263.1.
Turner, J., and Coauthors, 2009: Non-annular atmospheric circulation change induced by stratospheric ozone depletion and its role in the recent increase of Antarctic sea ice extent. Geophys. Res. Lett., 36, L08502, https://doi.org/10.1029/2009GL037524.

_ , T. J. Bracegirdle, T. Phillips, G. J. Marshall, and J. S. Hosking, 2013: An initial assessment of Antarctic sea ice extent in the CMIP5 models. J. Climate, 26, 1473-1484, https://doi.org/ 10.1175/JCLI-D-12-00068.1.

Valcke, S., 2006: OASIS3 User Guide. PRISM-Support Initiative Rep. 3, CERFACS TR/CMGC/06/73, 68 pp.

Wilcox, L. J., A. Charlton-Perez, and L. Gray, 2012: Trends in austral jet position in ensembles of high- and low-top CMIP5 models. J. Geophys. Res., 117, D13115, https://doi.org/10.1029/ 2012JD017597.

Wong, A. P. S., N. L. Bindoff, and J. A. Church, 1999: Large-scale freshening of intermediate waters in the Pacific and Indian Oceans. Nature, 400, 440-443, https://doi.org/10.1038/22733.

Xie, P., and P. A. Arkin, 1997: Global precipitation: A 17-year monthly analysis based on gauge observations, satellite estimates, and numerical model outputs. Bull. Amer. Meteor. Soc., 78, 2539-2558, https://doi.org/10.1175/1520-0477(1997)078<2539: GPAYMA $>2.0 . \mathrm{CO} ; 2$.

Zunz, V., and H. Goosse, 2015: Influence of freshwater input on the skill of decadal forecast of sea ice in the Southern Ocean. Cryosphere, 9, 541-556, https://doi.org/10.5194/tc-9-541-2015.

,$- \ldots$, and F. Massonnet, 2013: How does internal variability influence the ability of CMIP5 models to reproduce the recent trend in Southern Ocean sea ice extent? Cryosphere, 7, 451468, https://doi.org/10.5194/tc-7-451-2013. 